\title{
Cloud, Aerosol, and Boundary Layer Structure across the Northeast Pacific Stratocumulus-Cumulus Transition as Observed during CSET
}

\author{
Christopher S. Bretherton, IsAbel L. McCoy, Johannes Mohrmann, And Robert Wood \\ Department of Atmospheric Sciences, University of Washington, Seattle, Washington \\ VIRENDRA GHATE \\ Argonne National Laboratory, Argonne, Illinois
}

ANDREw GETTELMAN AND CHARLES G. BARDEEN

National Center for Atmospheric Research, Boulder, Colorado

Bruce A. Albrecht and Paquita Zuidema

Rosenstiel School of Marine and Atmospheric Science, University of Miami, Miami, Florida

(Manuscript received 29 November 2018, in final form 4 April 2019)

\begin{abstract}
During the Cloud System Evolution in the Trades (CSET) field study, 14 research flights of the National Science Foundation G-V sampled the stratocumulus-cumulus transition between Northern California and Hawaii and its synoptic variability. The G-V made vertically resolved measurements of turbulence, cloud microphysics, aerosol characteristics, and trace gases. It also carried dropsondes and a vertically pointing W-band radar and lidar. This paper summarizes these observations with the goals of fostering novel comparisons with theory, models and reanalyses, and satellite-derived products. A longitude-height binning and compositing strategy mitigates limitations of sparse sampling and spatiotemporal variability. Typically, a 1-km-deep decoupled stratocumulus-capped boundary layer near California evolved into 2-km-deep precipitating cumulus clusters surrounded by patches of thin stratus that dissipated toward Hawaii. Low cloud cover was correlated with estimated inversion strength more than with cloud droplet number, even though the thickest clouds were generally precipitating and ultraclean layers indicative of aerosol-cloud-precipitation interaction were common west of $140^{\circ} \mathrm{W}$. Accumulation-mode aerosol concentration correlated well with collocated cloud droplet number concentration and was typically largest near the surface. Aitken mode aerosol concentration was typically larger in the free troposphere. Wildfire smoke produced spikes of aerosol and trace gases on some flights. CSET data are compared with space-time collocated output from MERRA-2 reanalysis and from the CAM6 climate model run with winds and temperature nudged toward this reanalysis. The reanalysis compares better with the observed relative humidity than does nudged CAM6. Both vertically diffuse the stratocumulus cloud layer versus observations. MERRA-2 slightly underestimates in situ carbon monoxide measurements and underestimates ozone depletion within the boundary layer.
\end{abstract}

\section{Introduction}

The climatological stratocumulus to cumulus $(\mathrm{Sc}-\mathrm{Cu})$ transition over the eastern subtropical oceans has been a long-standing test of our physical understanding and modeling skill. Through a combination of field and satellite observations and detailed process modeling such as large-eddy simulation (LES), the $\mathrm{Sc}-\mathrm{Cu}$ transition has

Corresponding author: Christopher S. Bretherton, breth@uw.edu been explained as due to the deepening and warming of a cloud-topped marine boundary layer under a strong inversion as it advects toward warmer sea surface temperature (SST) in the subtropical trade winds (Krueger et al. 1995a,b; Wyant et al. 1997; Bretherton and Wyant 1997). Strong mean subsidence over cool coastal waters maintains a shallow, fairly well-mixed stratocumulus boundary layer capped by a strong inversion. The boundary layer deepens as it advects away from the coast toward higher SST and weaker mean subsidence, 
driving decoupling between surface-driven and cloud-top driven turbulent layers connected by a layer of shallow cumulus clouds. Farther downstream, warming of the boundary layer supports deeper and more vigorous cumuli that mix down enough dry free-tropospheric air and may precipitate out enough water to bring down the inversion-base relative humidity and evaporate the capping stratocumulus, completing the transition.

Countless field studies have sampled stratocumulustopped boundary layers within $1000 \mathrm{~km}$ of the California coast. There are far fewer detailed in situ observations farther offshore where the stratocumulus gradually breaks up. The 1992 Atlantic Stratocumulus Transition Experiment (ASTEX), based in the northeast Atlantic, documented the persistently decoupled nature of the cumulus-under-stratocumulus boundary layers in this transitional regime and was among the first field studies to use ground-based millimeter-wavelength radars for studying boundary layer cloud and precipitation processes and their mesoscale organization (Albrecht et al. 1995). ASTEX included two 2-day intensive observing periods in which the Lagrangian evolution of cloudy boundary layers was tracked by aircraft (Bretherton and Pincus 1995; Bretherton et al. 1995). The first of these cases, in which partial breakup of $\mathrm{Sc}$ into $\mathrm{Cu}$ was observed, was subsequently used for model intercomparisons (Bretherton et al. 1999; van der Dussen et al. 2013).

The GCSS Pacific Cross-Section Intercomparison (GPCI) (Teixeira et al. 2011) created summertime climatologies of a suite of remote sensing observations and reanalysis outputs along a vertical section stretching from the California coast past Hawaii to the central Pacific ITCZ. These were compared with a large group of global numerical weather prediction and climate models to identify biases in the simulated vertical atmospheric structure and cloud distribution, with particular attention to the cloud-topped boundary layer and the $\mathrm{Sc}-\mathrm{Cu}$ transition.

The GPCI motivated the MAGIC (Marine ARM GPCI Investigation of Clouds) project in 2012-13. MAGIC deployed the Department of Energy Atmospheric Radiation Measurement Mobile Facility (AMF2) on a container ship that traversed between Long Beach, California, and Honolulu, Hawaii. The AMF2 included rawinsondes, vertically pointing cloud radars, a micropulse lidar, aerosol, cloud, radiation, and meteorological measurements. MAGIC sampled through the $\mathrm{Sc}-\mathrm{Cu}$ transition on numerous cruises across the annual cycle, as documented by Zhou et al. (2016) and Kalmus et al. (2014). MAGIC data have been comprehensively compared with large-eddy simulations of many of the cruises (McGibbon and Bretherton 2017) as well as satellite retrievals (Painemal et al. 2015), global weather forecast model output (Ahlgrimm et al. 2018), and reanalysis (Kalmus et al. 2015).

The focus of this paper is the Cloud System Evolution in the Trades (CSET) campaign in July-August 2015 (Albrecht et al. 2019; hereafter A19). CSET aimed to document and understand cloud processes in the summertime $\mathrm{Sc}-\mathrm{Cu}$ transition using airborne measurements between California and Hawaii that complement past surface-based and satellite observations.

CSET goals, strategy, and observations were described in detail by A19, as was the instrumentation aboard the National Science Foundation Gulfstream-V (G-V) research aircraft. For this study, we will use the seven flight pairs RF02-03, RF04-05, ..., RF14-15, each of which started with a westbound flight from Sacramento, California, to Kona, Hawaii, followed 2 days later by an eastbound flight. Figure 1 shows these flight tracks, with solid blue lines for westbound flights and dashed blue lines for eastbound flights, superposed on a geostationary satellite-derived estimate of low cloud fraction (detailed in section 2a) for the CSET period of 1 July-15 August 2015. The thickened regions of the tracks indicate low-level sampling, while the thin regions indicate survey legs during which the G-V was flying at approximately $6-\mathrm{km}$ altitude. Figure 1 also shows the nearby GPCI and MAGIC cross sections in red. The solid yellow lines indicate a coordinate system discussed in section 2 that we will use for CSET data analysis.

CSET sampling provided an unprecedentedly rich and extensive suite of observations of the cloud-topped boundary layer between California and Hawaii. The CSET flight plans were based on a Lagrangian lowlevel sampling strategy for the eastbound flights, as described by A19 and scientifically exploited in the analysis of Mohrmann et al. (2019, manuscript submitted to Mon. Wea. Rev.). Because of this strategy, the low-level sampling on the eastbound flights was typically substantially farther downwind (south and west) than on the westbound flights, as can be seen on Fig. 1. The CSET flights also provided a comprehensive quasi-Eulerian sampling of the $\mathrm{Sc}-\mathrm{Cu}$ transition.

In this paper, we use this dataset to describe the boundary layer, clouds, and aerosols during each flight, with three main goals. Our first goal is to develop a composite description of the transition suitable for comparison with regional summertime climatology simulated by climate models, with an emphasis on those measurements unique to CSET. Our second goal is to briefly characterize day-to-day variability of the $\mathrm{Sc}-\mathrm{Cu}$ transition and compare the space-time variation of cloud 


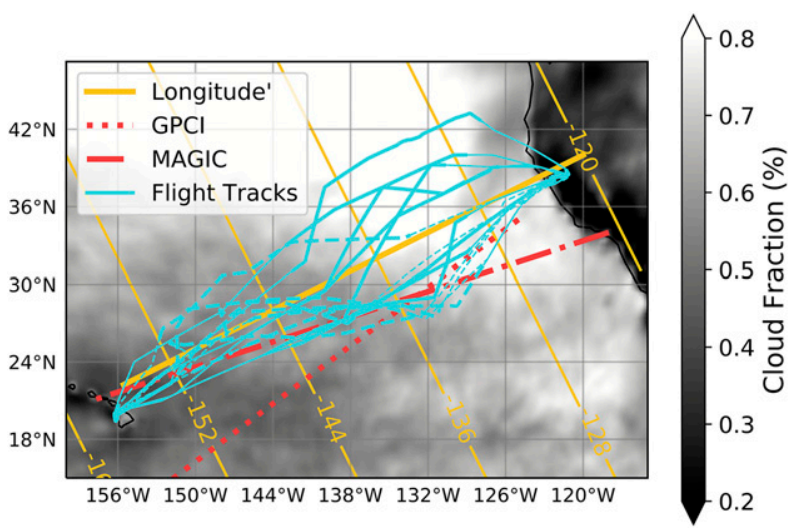

FIG. 1. CSET flight tracks (blue lines) between Sacramento, CA, and Kona, HI, overlaid on the mean GOES-derived low cloud fraction over the CSET study period (1 Jul-15 Aug 2015). Blue lines are thin during survey legs, thick during low-level sampling, solid for westbound flights, and dashed for eastbound flights. The dotted red line is the GPCI transect, the chain dashed red line is the approximate route of the MAGIC container ship, the thick solid yellow line indicates the reference axis of the lon' coordinate described in section $2 \mathrm{c}$, and the thin solid yellow lines show lon' in $8^{\circ}$ increments.

properties with our current understanding, including the correlation with "cloud-controlling factors" such as the estimated inversion strength (EIS) (Wood and Bretherton 2006) and aerosol concentration. Our third goal is to demonstrate the potential for comparing data from individual flights with observationally constrained global model simulations sampled along the flight tracks, to evaluate model performance in this challenging regime. This includes reanalysis, as well as climate model simulations with winds and temperature (but not humidity, clouds, and aerosol) nudged toward reanalysis. We attempt to average across the prominent mesoscale organization seen in the cloudy boundary layers of this region, focusing on space scales of $500 \mathrm{~km}$ or more for which the CSET flights provide more representative sampling.

In section 2, we briefly summarize the observations used and we describe our binning and compositing technique. We demonstrate that the aircraft-based sampling is sufficiently representative to serve as a rough climatology. Sections $3 a$ and $3 b$ present the basic CSET-composite thermodynamic structure across the $\mathrm{Sc}-\mathrm{Cu}$ transition and its flight-to-flight variability. With this context, the remainder of the paper emphasizes vertically resolved measurements across this transect that are unique to CSET. Sections $3 \mathrm{c}$ and $3 \mathrm{~d}$ analyze turbulence and trace gas concentrations. Section 4 presents cloud microphysics, in situ aerosol, lidar-radar-derived cloud extent and radar-derived precipitation. Section 5 uses the binned results to test the correlation of low cloud cover with two potential cloudcontrolling factors, inversion stability and cloud droplet number concentration. Section 6 compares observations from an illustrative CSET flight with reanalysis and a weather-nudged climate model, followed by a summary in section 7 .

\section{CSET observations and analysis methods}

\section{a. Measurements used in this study}

The G-V instrumentation used for CSET was described in detail by A19. It included a $94-\mathrm{GHz}$ cloud radar, a high spectral resolution lidar, dropsondes, and in situ probes for basic meteorology, cloud microphysics, aerosol, up- and downwelling radiation, ozone, and carbon monoxide. All G-V data analyzed here were obtained from the National Center for Atmospheric Research Earth Observing Laboratory CSET data archive (https://www.eol.ucar.edu/field_projects/cset). For our study, most in situ measurements are analyzed at $1-\mathrm{Hz}$ frequency. The G-V has faster-response sensors for several of these quantities, such as velocity components. This study will introduce a $1-\mathrm{Hz}$ proxy for dissipation rate of turbulent kinetic energy derived from the $25-\mathrm{Hz}$ vertical velocity measurements.

Some aircraft measurements are compared with products from NOAA's Geostationary Operational Environmental Satellite-15 (GOES-15), provided to CSET by NASA Langley's SatCORPS group as described in A19 (and downloaded from https://satcorps.larc.nasa.gov). Our study uses low cloud fraction computed at 15-min frequency based on pixels of $4 \mathrm{~km}$ size at nadir using GOES visible and infrared imagery to determine cloud-top phase, temperature, and height (Minnis et al. 2008).

For comparison with flight data, a time-matched subset of GOES data over a $2^{\circ} \times 2^{\circ}$ box centered on the aircraft is extracted. The low cloud fraction is defined as the fraction of cloud-filled pixels (based on a reflectance threshold) identified as warm (liquid phase with cloud top temp $>273 \mathrm{~K}$ ) and low (cloud top height $<4 \mathrm{~km}$ ). The box size is chosen to encompass a large enough area around the aircraft to represent the cloud statistics in the surrounding region by smoothing across mesoscale cloud variability. Thus the GOES cloud fraction will not be identical to the point cloud fraction measurement made by the aircraft. We also use cloud droplet concentration $N_{d}$ derived following Painemal and Zuidema (2011) by combining single-pixel cloud optical depth and effective radius retrievals. To mitigate possible biases due to subpixel cloud inhomogeneity and partly cloud-filled pixels, we use the 
75th percentile of the $N_{d}$ s sorted from low to high over all low cloud pixels within the $2^{\circ} \times 2^{\circ}$ box.

\section{b. CSET sampling strategy}

By design, CSET surveyed the lower atmospheric structure across large distances while flying at varying heights in and above the cloud-topped boundary layer. As a result, the CSET in situ sampling was sparse and inhomogeneous. In addition, the cloud structures had ubiquitous mesoscale variability on scales of tens to hundreds of kilometer, and each flight followed a different track in a different synoptic setting. These challenges shaped our compositing method and affect its representativeness. We will briefly summarize the CSET flight patterns, shown in Fig. 4 of A19.

The CSET flights began and ended with survey legs at about $6 \mathrm{~km}$ altitude, typically launching dropsondes every $2^{\circ}$ of longitude. The central part of the CSET flights consisted of $2000-2500 \mathrm{~km}$ of low-level sampling, repeating "modules" consisting of 10-min level legs at 150-m altitude, within the cloud layer, and approximately $300 \mathrm{~m}$ above the cloud layer, and sawtooth legs that sampled across the cloud layer and the capping inversion. The left column of A19's Fig. 7 shows radar, lidar, and geostationary satellite views of a typical flight RF10 (27 July 2015) through the Sc-Cu transition that we will use as an illustrative example throughout this paper, following A19. This figure illustrates the pronounced small-scale and mesoscale variability in cloud and precipitation sampled during each CSET flight. Four low-level sampling modules were completed on this flight. The first module went in a near southerly direction, so it is almost collapsed in the longitudeheight presentation of A19's Fig. 7. This motivates our use of a modified longitude coordinate (section 2c) for single-flight analysis and multiflight compositing.

The flight pairs were planned such that the eastbound flights resampled the same boundary layer air mass as sampled on the westbound flights two days earlier, as estimated from isobaric trajectories initialized at 500-m altitude (approximately $960 \mathrm{hPa}$ ) from NCEP operational analyses and short-range forecasts (A19). The westbound low-level sampling was weighted toward stratocumulus which was projected to break up as it advected downwind over the following 2 days. The eastbound low-level sampling was substantially farther south and west, as can be seen by comparing the thick dashed lines and the thick solid lines in Fig. 1, and predominantly sampled shallow cumulus cloud.

\section{c. Longitude-height binning}

For statistical analysis of day-to-day variability and for developing as representative a summertime "climatology" as possible from the CSET observations, we use longitude-height binning. This approach takes advantage of as much of the G-V data as possible, including ascents and descents as well as level legs. First, we define a simple modified longitude coordinate that we use to measure distance along the transect:

$$
\begin{aligned}
& \operatorname{lon}^{\prime}=\operatorname{lon}_{0}+0.8\left(\text { lon }-\operatorname{lon}_{0}\right)+0.4\left(\text { lat }- \text { lat }_{0}\right), \\
& \operatorname{lon}_{0}=-140^{\circ} \mathrm{E}, \quad \operatorname{lat}_{0}=30^{\circ} \mathrm{N} .
\end{aligned}
$$

Figure 1 shows contours of lon' as thin northwest (NW)southeast (SE)-oriented solid yellow lines. Along the orthogonal thick solid yellow line extending approximately from Kona to Sacramento, lon' is equal to the true longitude. Thus, the use of lon' projects the flight data onto a longitude-height section following that central line. This coordinate has two advantages over our initial choice of using unmodified longitude while retaining a simple mathematical form. First, contours of the climatological cloud fraction and estimated inversion strength trend NW-SE in this region. Hence lon' $^{\prime}$ is optimized for distilling the systematic variations in cloud and boundary layer properties across the $\mathrm{Sc}-\mathrm{Cu}$ transition. In particular, use of lon' mitigates biases due to the Hawaii-California flights being systematically south of the California-Hawaii flights, and therefore tending to sample a lower cloud fraction and higher EIS at a given longitude. Second, with one exception, flight paths never doubled back over the same lon'. That is, for each flight there is a unique correspondence between elapsed time and lon'. In contrast, several flights had nearly north-south sections of low-level sampling that collapse when projected onto regular longitude.

We specify a bin size in lon' and altitude $z$. For any given field and for each flight, we bin all of the $1-\mathrm{Hz}$ samples into $\operatorname{lon}^{\prime}-z$ bins. For fields measured by the dropsondes, those measurements are also included in this binning. On any given flight, some such bins will be unsampled, some will have a few samples (e.g., where the aircraft was ascending or descending at $7.5 \mathrm{~m} \mathrm{~s}^{-1}$ ), and some will be sampled during level flight legs and include hundreds or thousands of samples). For each field, we compute a bin mean, except for outlier-prone fields (cloud droplet number concentration, aerosol number concentrations, and chemical tracers), for which we compute a bin-median. We experimented with only retaining bins with a minimum number of $1-\mathrm{Hz}$ samples (e.g., 10), but this did not yield obvious improvements.

A few fields can only be usefully computed with conditional sampling. The cloud droplet concentration $N_{d}$ is only used in cloud, empirically defined as where $1-\mathrm{Hz}$ cloud liquid water content measured by the Cloud Droplet Probe (CDP) exceeds $0.01 \mathrm{~g} \mathrm{~m}^{-3}$. 
(a)

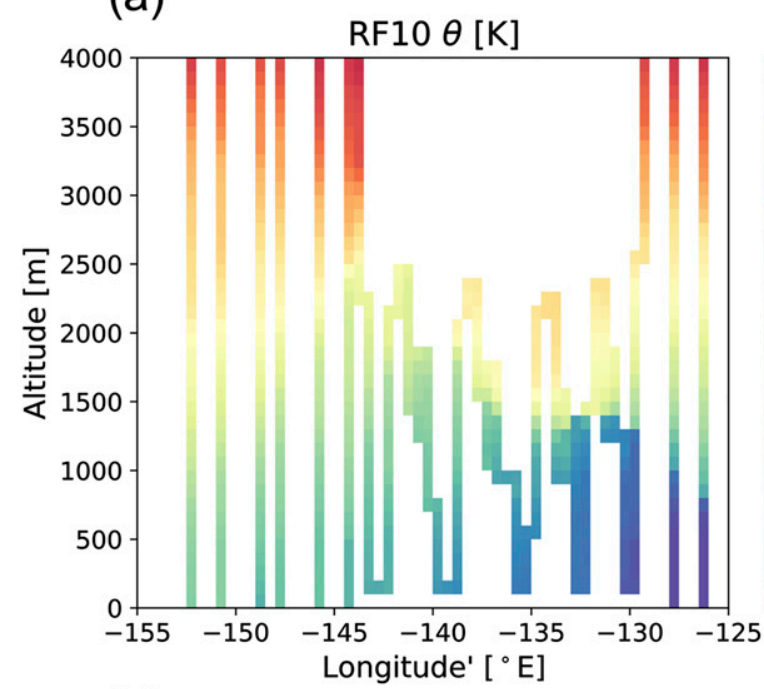

(c)

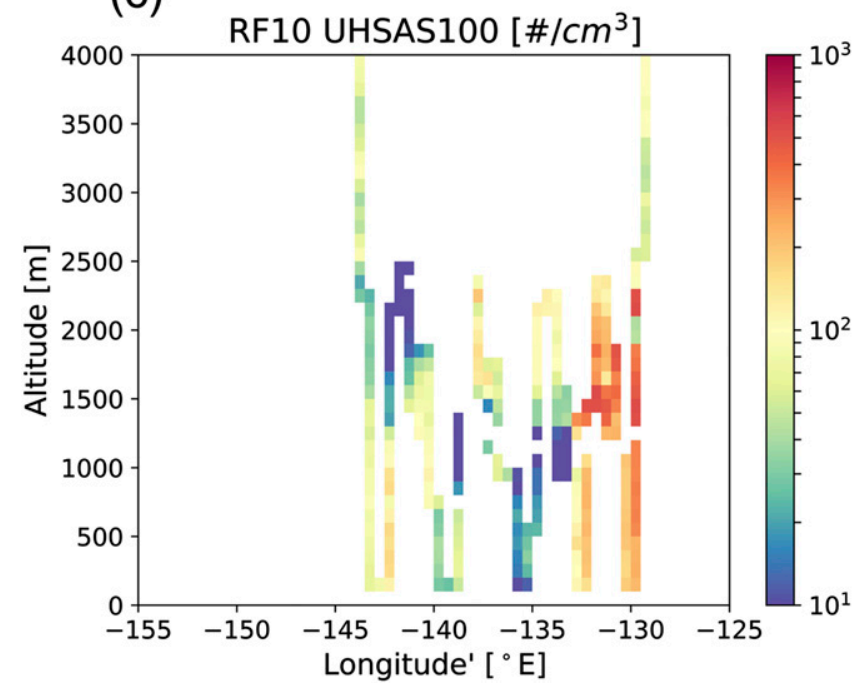

(b)

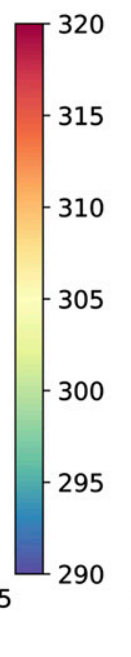

(d)

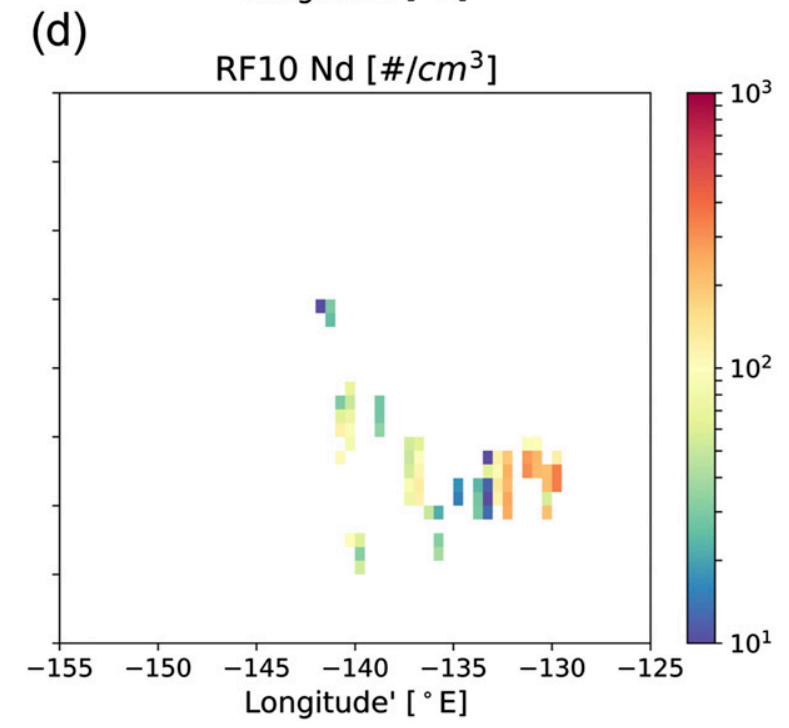

FIG. 2. (a) Potential temperature, (b) relative humidity, (c) accumulation mode aerosol concentration UHSAS100, and (d) cloud droplet number concentration $N_{d}$ for a representative flight RF10, using bins of $0.5^{\circ}$ in lon' and $100 \mathrm{~m}$ in $z$ that resolve the aircraft flight path.

Two measured aerosol number concentrations, UHSAS100 (aerosol particle concentration in the $100-1000 \mu \mathrm{m}$ diameter range, the "accumulation mode" (Rogers and Yau 1989, p. 93) and CN (concentration of aerosol particles on which gas vapors can condense in the diameter range $10-1000 \mu \mathrm{m})$, can be contaminated by shattering of cloud and precipitation droplets. They are only used where the CDP detects less than $0.01 \mathrm{~g} \mathrm{~m}^{-3}$ of liquid water and the concentration of precipitation-size drops with radii $>31 \mu \mathrm{m}$ detected by the G-V $2 \mathrm{D}-\mathrm{C}$ optical array probe is less than $1 \mathrm{~L}^{-1}$ (empirically chosen thresholds). Temperature, humidity, and winds are sampled by the dropsondes as well as in situ measurements. For these fields, both data sources are used for the binning; in any flight they mostly sample mutually exclusive lon' $-z$ bins .
Figure 2 shows some examples for a representative flight RF10, using bins of $0.5^{\circ}$ in lon' $^{\prime}$ and $100 \mathrm{~m}$ in $z$ that resolve the aircraft flight path. Figure 2 a shows potential temperature $\theta$. East of $\operatorname{lon}^{\prime}=-140^{\circ}\left(140^{\circ} \mathrm{W}\right)$, a sharp vertical increase in $\theta$ marks the trade inversion; farther west $\theta$ instead shows a broad vertical layer of stable stratification. Figure $2 \mathrm{~b}$ shows relative humidity. The high relative humidity (red shades) marks the cloudy boundary layer and is capped by the trade inversion where present. Vertical columns in Figs. 2a and 2b show dropsonde measurements during the survey legs. The more irregular measurement coverage in the center is from in situ measurements during four low-level sampling modules, during which there are no measurements more than $1 \mathrm{~km}$ above the boundary layer top. 
(a)

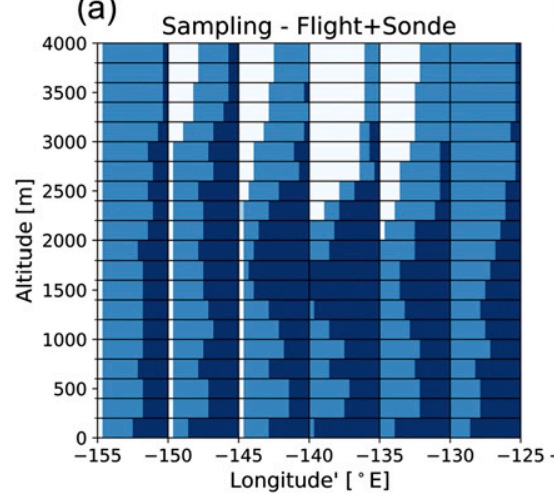

(b)

Sampling - Flight

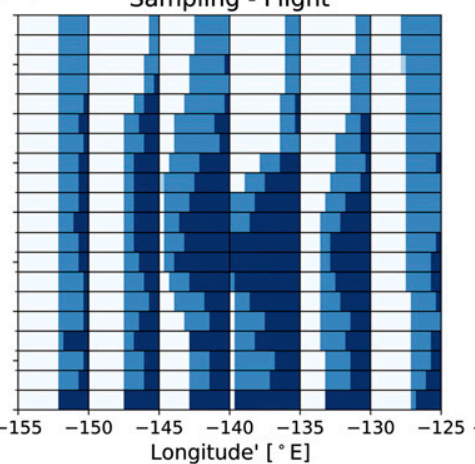

(c)

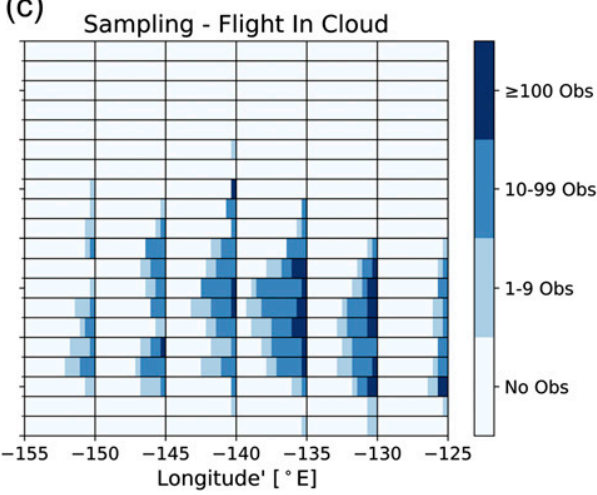

FIG. 3. Sampling representativeness of bins of $5^{\circ}$ in $\operatorname{lon}^{\prime}$ and $200 \mathrm{~m}$ in $z$ for (a) combined G-V and radiosonde measurements, (b) G-V in situ measurements, and (c) G-V in-cloud measurements only. For each bin in each panel, the fraction of the flights including no, 1-10, 11-100, and 101+ 1-Hz measurements is colored in white, light blue, medium blue, and dark blue, respectively.

Figure 2c shows the UHSAS100 (accumulation-mode aerosol) concentration. Small gaps along the flight track show where it has been screened to avoid clouds and precipitation. It shows large horizontal variability both in and above the boundary layer. Figure $2 \mathrm{~d}$ shows the lon' $-z$ bin-average $N_{d}$, which is only used inside of clouds. This drastically reduces the sampling of bins during each flight, making it very spotty and less statistically robust.

To get representative spatial averages in the face of sparse sampling, we use coarser averaging bins of $5^{\circ}$ in $l^{\prime}{ }^{\prime}$ and $200 \mathrm{~m}$ in $z$ for the remainder of this paper. The low-level sampling modules typically span $3^{\circ}-4^{\circ}$ in lon', so within a $5^{\circ} \operatorname{lon}^{\prime}$ bin, they are sure to sample the full range of altitudes spanned by the module. The 150-m subcloud legs populate the lowest altitude bin and sampling typically extends at least $500 \mathrm{~m}$ above the trade inversion. Within the survey legs, dropsondes were typically released every $2^{\circ}$ of longitude, so two or more dropsondes are included in each lon' bin.

\section{d. All-fight compositing}

The composite lon' $-z$ cross sections presented later in this paper are averages over the binned cross sections for each flight. By definition, only those flights that sampled each bin contribute to the bin average. Figure 3 shows the representativeness of such averaging. For each bin, we calculate the fraction of flights with no samples in that bin, and color that fraction of the bin in white. The fraction of the flights with over 100 samples in a particular bin is shaded dark blue, with $10-100$ samples in medium blue, and with $1-10$ or less in light blue.

Figure 3a shows the bin sampling of quantities like $\theta$ or humidity that are measured both in situ and by radiosonde. These quantities are uniformly well sampled by dropsonde in the survey legs. Within the low-level modules, they are well sampled in situ up to $500 \mathrm{~m}$ above the local cloud-top heights. Through this combination of observations, all flights contribute to the bin-average at altitudes below $2200 \mathrm{~m}$. Fewer flights contribute observations at higher altitudes for longitudes at which many flights were doing low-level sampling. These come either from particularly deep boundary layers or from surveyleg dropsondes on the remaining flights that sampled air masses with unusual trajectories. For instance, at $\operatorname{lon}^{\prime}=$ $135^{\circ}-140^{\circ} \mathrm{W}$, only two to three flights sampled above $2600 \mathrm{~m}$, so an "all-flight" composite will average over as few as two flights and may not be representative.

Figure $3 \mathrm{~b}$ shows the same presentation for quantities that are continuously measured in situ but not measured by radiosonde. The bins near the center of the transect are well-sampled below $2400 \mathrm{~m}$, but near Hawaii and California, only about half of the flights contributed aircraft profiles.

In both Figs. 3a and 3b, all bins sampled on a given flight have at least 10 contributing $1-\mathrm{Hz}$ measurements (with one exception in Fig. 3b). Figure 3c shows the sampling of cloud droplet concentration $N_{d}$, which is only calculated when the aircraft is flying through cloud. For $N_{d}$, numerous bins on several flights have 1-10 contributing $1-\mathrm{Hz}$ samples. This sparse sampling makes an all-flight composite of $N_{d}$ particularly uncertain. A crude way to visually assess that uncertainty is to look at variability between adjacent $l^{\prime}{ }^{\prime}-z$ grid cells.

For radar reflectivity, all averaging bins are sampled on all flights. The G-V radar and lidar pointed downward during the survey legs, thus sampling the entire 0-4-km layer. During in situ sampling, the radar and lidar were frequently flipped between upward and downward viewing, providing samples over the full atmospheric column within each $5^{\circ}$ bin. The lidar beam 
(a)

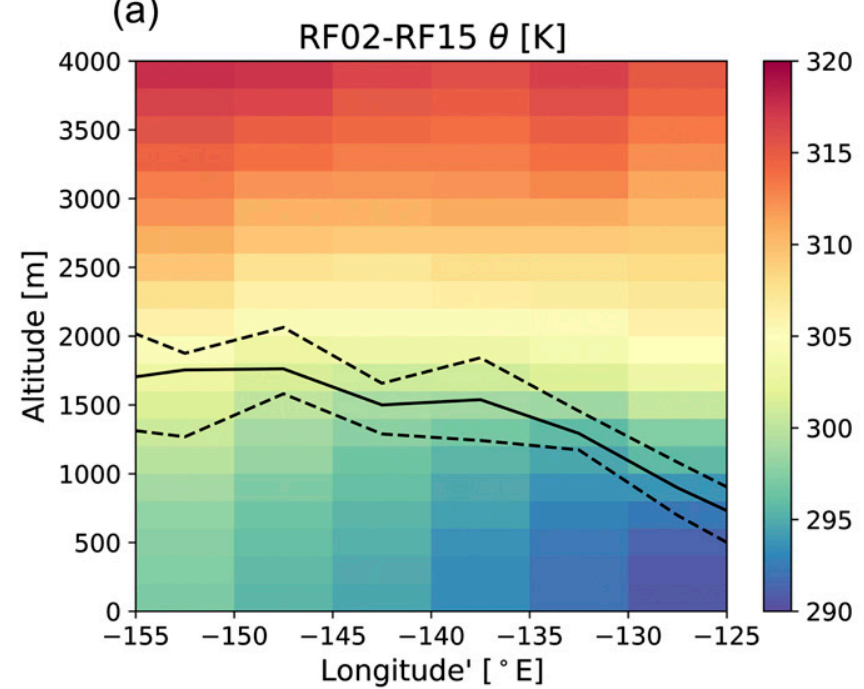

(b)

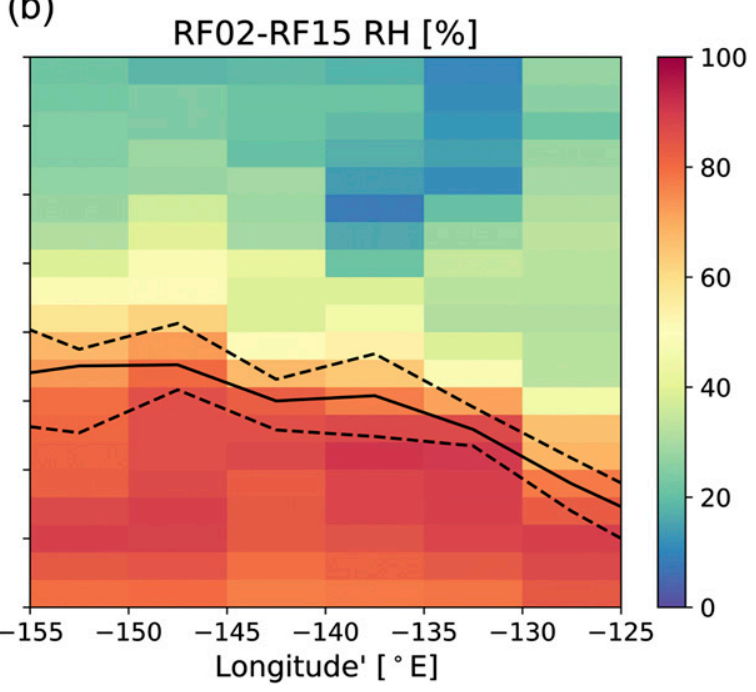

FIG. 4. All-flight composite potential temperature $\theta$ and relative humidity RH in the lower troposphere sampled by the 14 CSET crosssectional flights, including both in situ and dropsonde data. Solid black line indicates all-flight composite inversion base (see text) and dashed lines indicate its interquartile range across contributing flights.

was often fully attenuated by cloud, but only rarely across a full $5^{\circ}$ bin.

The all-flight composite is also subject to various possible sampling biases. For instance, certain synoptic conditions lead to different trajectories that must be sampled with different flight plans, our sampling favored conditions and regions without extensive high cloud, and the low-level sampling on eastbound flights was typically south and west of the westbound low-level sampling. To compare CSET data to a model constrained to have realistic time-varying meteorology for the CSET period, an ideal approach is to sample the model in time and space along the flight tracks, as done in section 6 . However, some climate models may not be practical to run and sample in this way. In that case, all-flight composites of observations unique to CSET (i.e., for which a reanalysis or satellite retrieval does not provide trustworthy information, such as the vertical profile of rainwater content or ozone) provide a convenient and worthwhile comparison to the summertime climatology from a climate model, because even a substantial representativeness uncertainty may still be much smaller than the model bias.

\section{Boundary layer structure and vertical mixing}

\section{a. Composite thermodynamic structure}

Figure 4 shows the composite structure of potential temperature $\theta$ and relative humidity $\mathrm{RH}$ in the lower troposphere sampled by the 14 CSET cross-section flights, including both in situ and dropsonde data. In the CSET study region, there is typically an inversion layer whose base coincides with the top of any boundary layer stratocumulus. For each flight the Heffter (1980) method was used to diagnose the height of the inversion base from all individual aircraft and dropsonde profiles. This inversion base was averaged across $5^{\circ} \operatorname{lon}^{\prime}$ bins for inclusion in this and other plots. The solid black line is the mean inversion base across all flights, and the dashed black lines indicate the interquartile range of inversion base between flights. As expected, the mean inversion base slopes upward to the west from $750 \mathrm{~m}$ near the coast to nearly $2 \mathrm{~km}$ west of $145^{\circ} \mathrm{W}$, and there are strong vertical gradients of $\theta$ and $\mathrm{RH}$ centered around this height, somewhat sharper nearer the coast. The RH profile has a local maximum at an altitude of $500 \mathrm{~m}$ to the west of $140^{\circ} \mathrm{W}$, suggestive of the climatological base of a cumulus layer that rises into any overlying stratocumulus.

\section{b. Decoupling}

The vast majority of individual CSET profiles show significant vertical humidity gradients below the main inversion, evidence of boundary layer decoupling. Figure 5 shows $\Delta q$, the difference in humidity between samples in the lowest $25 \%$ of the boundary layer and the uppermost $25 \%$ of the boundary layer, based on G-V profiles and dropsonde soundings from all CSET flights. Jones et al. (2011) characterized $\Delta q>0.5 \mathrm{~g} \mathrm{~kg}^{-1}$ as a decoupled boundary layer. Over $95 \%$ of the profiles or soundings are decoupled, and the decoupling index increases to the west as the typical inversion base deepens. 


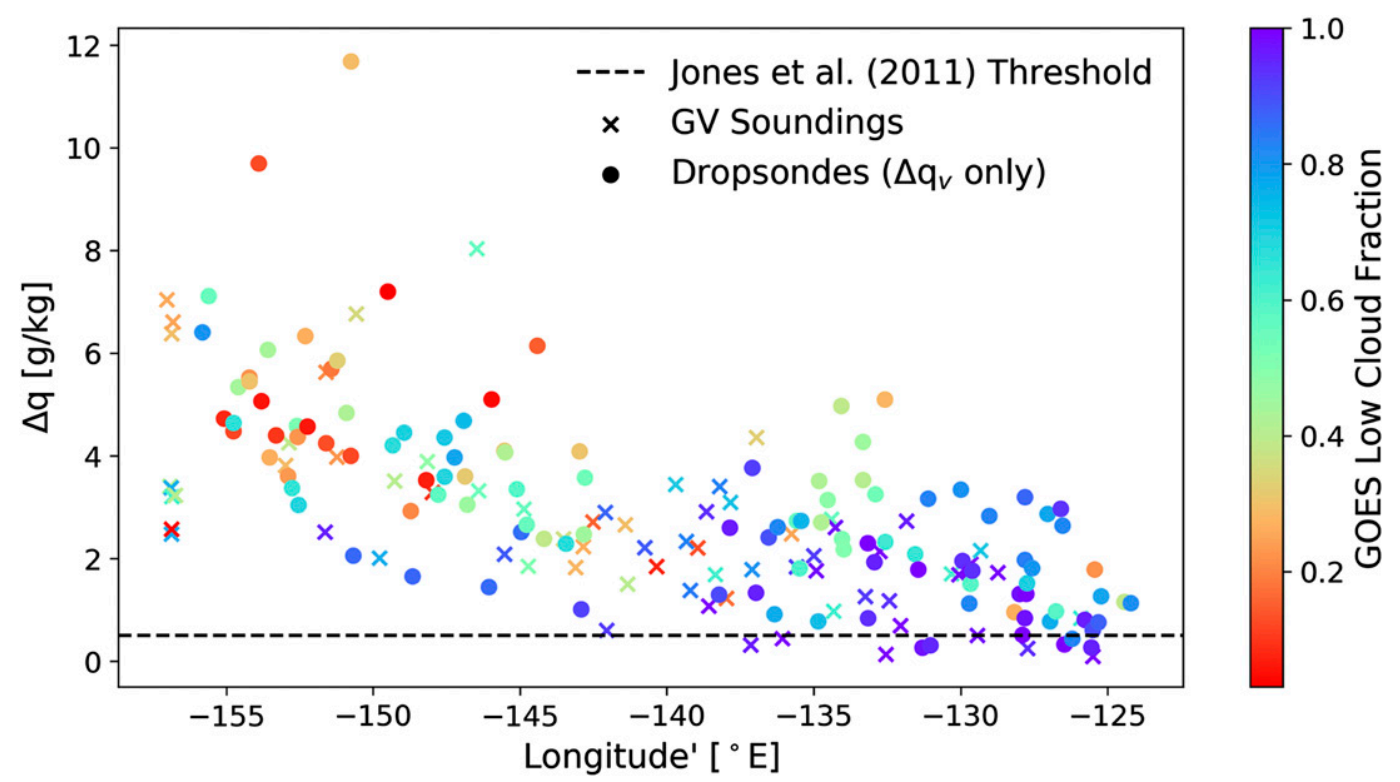

FIG. 5. Decoupling index $\Delta q$, the difference in humidity between samples in the lowest $25 \%$ of the boundary layer and the uppermost $25 \%$ of the boundary layer, based on G-V profiles (crosses) and dropsonde soundings (filled circles) from all CSET flights. Symbols are colored by the GOES-derived low cloud fraction in a $2^{\circ} \times 2^{\circ}$ box centered on the profiles.

All points in Fig. 5 are colored by the GOES-derived low cloud fraction in a $2^{\circ} \times 2^{\circ}$ box centered on the sounding location. There is a clear but imperfect correlation between $\Delta q$ and cloud fraction. The well-mixed soundings with $\Delta q<0.5 \mathrm{~g} \mathrm{~kg}^{-1}$ are all in $100 \%$ cloudy stratocumulus layers, but there are many more profiles with $80 \%-100 \%$ cloud fraction that have $\Delta q$ as large as $4 \mathrm{~g} \mathrm{~kg}^{-1}$. Many profiles west of $145^{\circ} \mathrm{W}$ have high decoupling index and low cloud fraction, indicative of a trade cumulus regime, but there are numerous exceptions. CSET lidar profiles often had less aerosol backscatter between the lowest cloud bases and the inversion than in the subcloud layer, consistent with decoupling (A19).

\section{c. Turbulence}

Approximately half of the CSET low-level sampling consisted of constant-altitude legs, either at $150 \mathrm{~m}$, or within or above the main cloud layer. One could estimate vertical velocity variance or turbulent fluxes from these legs, but very few estimates are obtained for each flight, and the ubiquitous mesoscale variability diminishes the representativeness of those estimates.

Instead, as an example of an alternative interesting measure of turbulence that could usefully be compared with boundary layer parameterizations and large-eddy simulations, we introduce a new aircraft-based estimate of turbulent kinetic energy (TKE) dissipation rate $\varepsilon$ per unit volume using high-frequency vertical velocity variability. Figure 7 of Wood et al. (2018) shows how this high-frequency vertical velocity variability clearly discriminates between higher turbulence levels in thicker stratocumulus clouds than in the thin veil clouds that commonly formed in ultraclean layers sampled in CSET. TKE dissipation rate depends on the intensity and continuity of turbulence. Continuous weaker turbulence and intermittent stronger turbulence (e.g., in a cumulus cloud field) may produce comparable dissipation rates. TKE dissipation rate is strongly controlled by the buoyancy (and to a lesser extent, shear) production of turbulence in subtropical marine boundary layers. In the appendix we describe how we estimate $\varepsilon$ in $\operatorname{lon}^{\prime}-z$ bins for each flight. Our estimate assumes that within each bin, the vertical velocity variance is due to turbulence. Gravity waves in stable stratification, such as in the free troposphere, will alias into this estimate, but they have comparatively little small-scale vertical velocity variance. This estimate may be less representative where the turbulence is highly variable (e.g., in cumulus cloud regimes).

Figure 6a shows our estimate of $\varepsilon$ for RF10. Figure 6b shows the all-flight composite. In both cases, the dissipation rate estimates for the free troposphere are small and probably do not reflect truly turbulent flow. Between 500-m altitude and the trade inversion, dissipation is substantial but it has no clear trends in height or longitude that rise above the significant sampling 

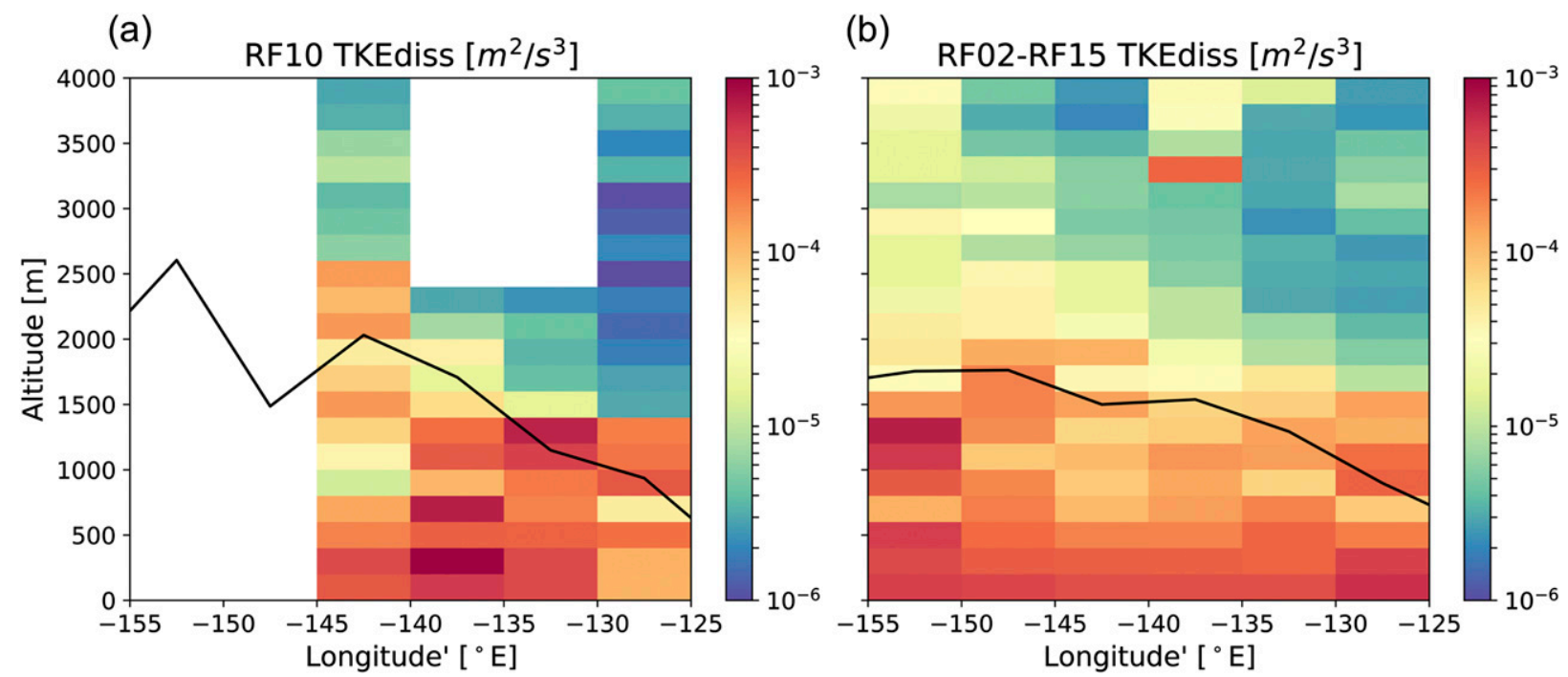

FIG. 6. TKE dissipation estimated from lon'-height binned high-frequency velocity variance as described in the appendix for (a) RF10 and (b) all-flight composite. High values at $135^{\circ}-140^{\circ} \mathrm{W}$ between 3 and $4 \mathrm{~km}$ are due to clear-air turbulence, mainly on flight RF09. Solid black line indicates inversion base.

variability. Below $500 \mathrm{~m}$, in the subcloud layer, we expect that the turbulence is surface-driven and more horizontally homogeneous, so dissipation estimates are thus more consistent across sampling bins, both in height and longitude. The all-flight composite dissipation estimates show an expected tendency to be larger near to the sea surface than within the cloud layer; this is less apparent in RF10 alone. Our estimates are comparable in magnitude and vertical structure to past measurements in stratocumulus (e.g., Lothon et al. 2005, Fig. 8) and largeeddy simulation of shallow cumulus (e.g., Cuijpers and Duynkerke 1993, Fig. 13).

\section{d. Trace species}

During CSET, the trace gases ozone $\left(\mathrm{O}_{3}\right)$ and carbon monoxide $(\mathrm{CO})$ were measured at $1 \mathrm{~Hz}$ using instrumentation described by A19. Figure 7 shows their allflight composites. These provide additional insight into boundary layer processes and are interesting references for chemical transport models (see section 6 for such a comparison).

Figure 7a shows lower ozone concentrations in the boundary layer than the free troposphere, as expected due to photolysis. At all altitudes, ozone also decreases slowly to the west, where recent advection from sources of continental smoke and pollution is less common.

Figure $7 \mathrm{~b}$ shows that $\mathrm{CO}$ has comparatively little vertical gradient across the trade inversion in this region because it does not have a strong boundary layer sink. It shows the same westward decrease at all altitudes as does $\mathrm{O}_{3}$, presumably for similar reasons.

\section{Clouds and aerosols}

\section{a. Cloud cover}

Figure 8 shows two all-flight composite estimates of the vertically resolved profile of cloud fractional coverage. The first (Fig. 8a) is derived from the aircraft Cloud Droplet Probe as described in section 2c. Because of the sparsity of the in situ sampling, this composite is noisy and its details are not robust. Nevertheless, some general trends are clear. There is substantial low cloud below the inversion in the east half of the cross section. Examination of individual flights shows this is mostly stratocumulus with underlying scud or cumulus cloud patches with lower bases. Some CSET westbound flights encountered very shallow PBLs with cloud tops less than $400 \mathrm{~m}$ at the start of their low-level sampling. Cloud bases could occasionally be less than $200 \mathrm{~m}$ there, even though fog was not encountered. Farther to the west, cloud is spread over a wide range of altitudes between $500 \mathrm{~m}$ and the mean inversion base. There is still some stratiform cloud (e.g., see Wood et al. 2018; A19), but it is thin and the weak inversion fluctuates in altitude such that a preferred altitude for cloud occurrence is not obvious.

The second composite (Fig. 8b) uses a joint cloud and precipitation occurrence mask created from the vertically pointing cloud radar and lidar (Schwartz et al. 2019). We use this joint "lidar-radar" mask because precipitation cannot be cleanly separated from cloud in the common occurrence that the lidar beam is fully attenuated. Because the lidar and radar sample all altitudes simultaneously in whichever orientation they are both pointed, this composite encompasses a larger 
(a)

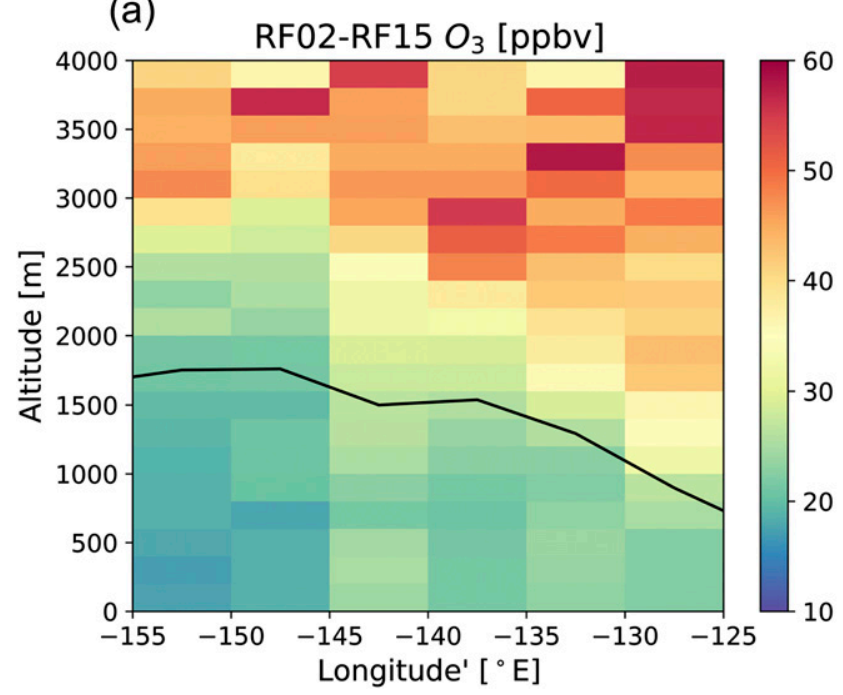

(b)

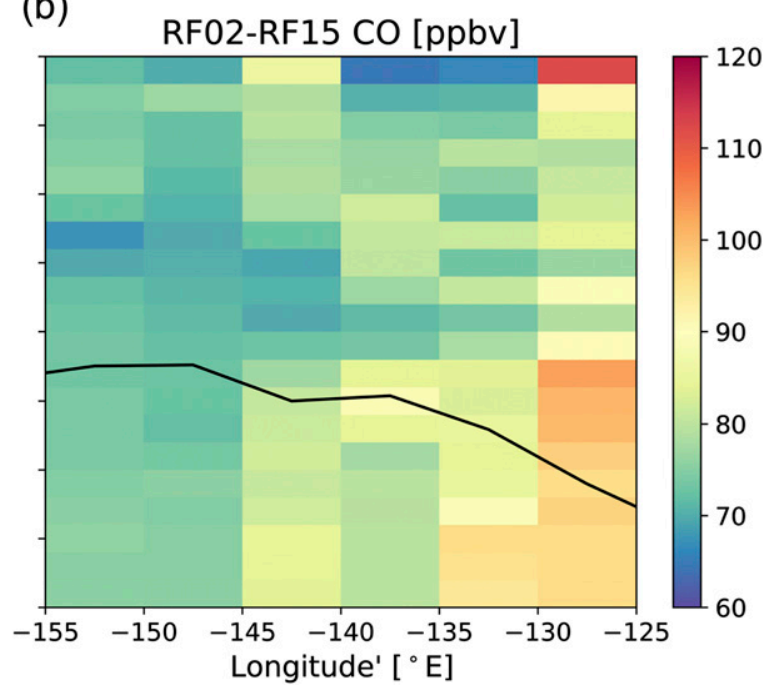

FIG. 7. All-flight composites of (a) ozone and (b) carbon monoxide. Solid black line indicates inversion base.

sampling domain and has less sampling variability. Reassuringly, it looks quite similar to the in situ cross section. Because it includes precipitation as well as cloud, the lidar-radar "cloud fraction" remains substantial below the actual cloud base (cf. Fig. 8b with Fig. 8a).

The vertically integrated low (altitude $<3 \mathrm{~km}$ ) cloud cover is particularly important because it is a strong control on the regional albedo. The lidar-radar mask can be used to detect the presence of any low cloud or precipitation above or below the aircraft. We assume that if there is low cloud in the column, the lidar is pointed in the appropriate direction to see it; this may occasionally not hold during sawtooths but overall is a good assumption. We also count a lidar-radar column as cloudy if the G-V Cloud Droplet Probe detects in situ cloud, because the lidar and/or radar may miss cloud that is so close to the aircraft as to lie within their respective dead zones (approximately 150 and $200 \mathrm{~m}$, respectively). Figure 9a shows the lidar-radar-derived low cloud fraction averaged in lon' bins for each flight (gray curves). It shows strong flight-to-flight variability with irregular cloud cover fluctuations between adjacent longitude bins. This emphasizes the synoptic and mesoscale variability of cloud within the $\mathrm{Sc}-\mathrm{Cu}$ transition. (a)

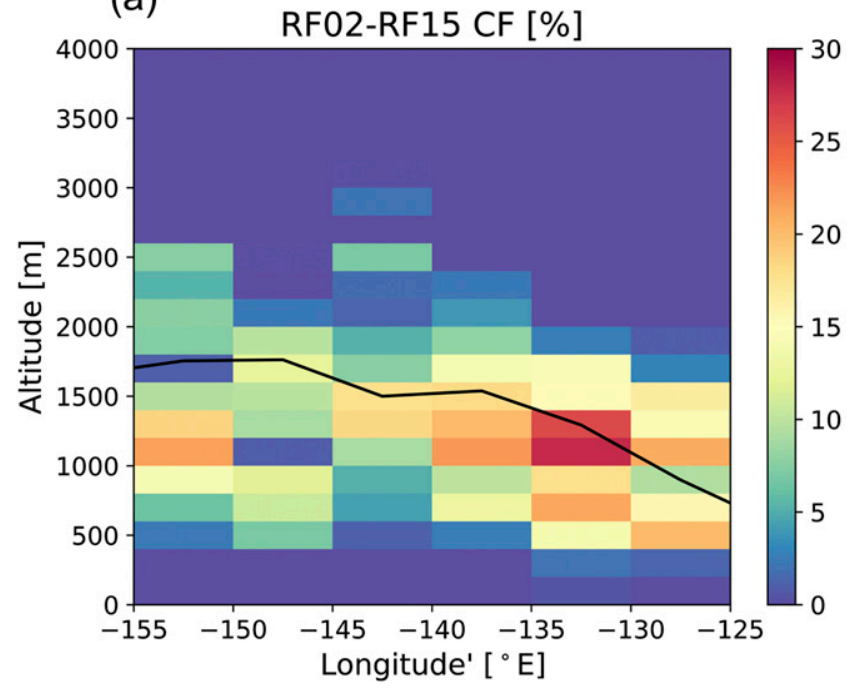

(b)

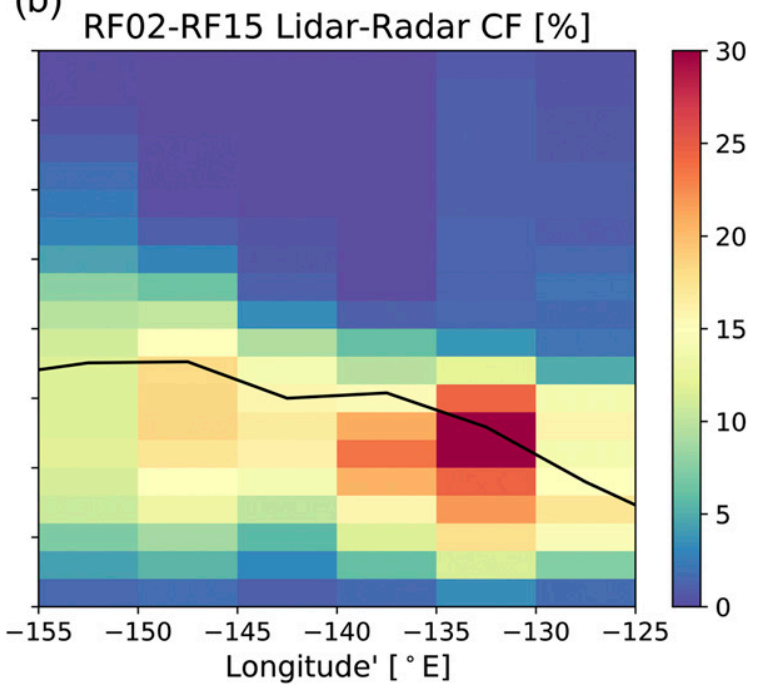

FIG. 8. All-flight composites of vertically resolved cloud fraction from (a) G-V Cloud Droplet Probe and (b) lidar-radar mask. Solid black line indicates inversion base. 
(a)

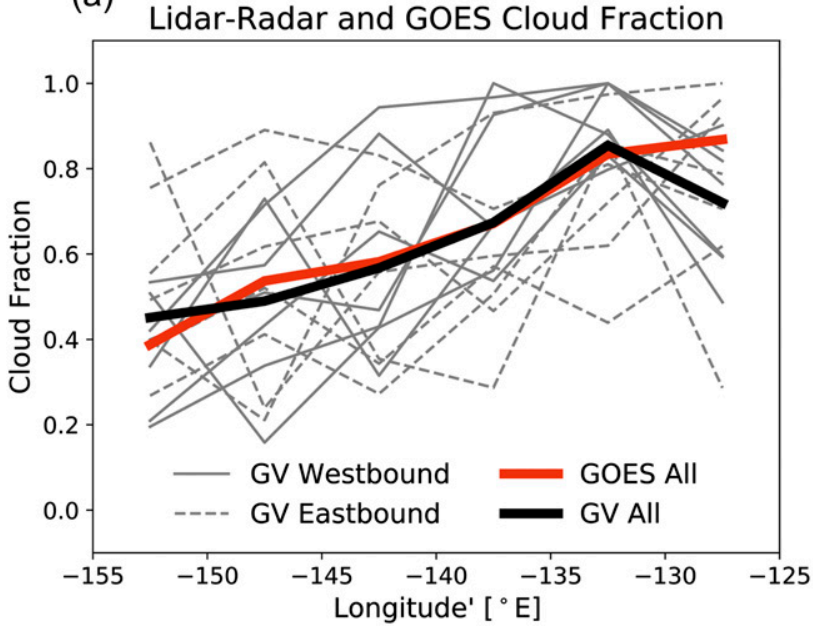

(b)

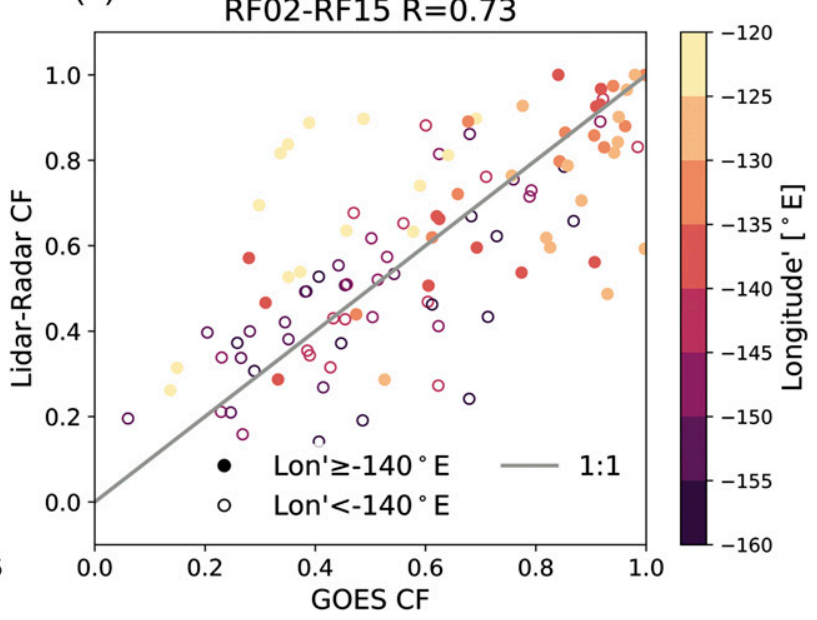

FIG. 9. (a) Lidar-radar low cloud fraction for individual flights averaged over $5^{\circ}$ lon' bins (thin gray lines; dashed for eastbound flights), all-flight mean (thick black line), and GOES $2^{\circ} \times 2^{\circ}$ boxes centered on the G-V and matched to its sampling time (red). (b) Scatterplot across all flights of bin-mean low cloud fraction from lidar-radar and GOES, colored and filled by lon'; $1: 1$ line is shown in gray and $R$ is the correlation coefficient.

Nevertheless, the all-flight mean low cloud cover (black) varies smoothly from 0.8 in the stratocumulus regime between $130^{\circ}$ and $135^{\circ} \mathrm{W}$ to 0.45 in the clustered cumulus regime west of $150^{\circ} \mathrm{W}$. Also shown is the allflight mean of the lon'-binned GOES-derived cloud cover (red), derived for each flight in a $2^{\circ} \times 2^{\circ}$ box centered on the flight location and matched within $15 \mathrm{~min}$ in time. This shows a very similar trend as the lidar-radar low cloud cover but is higher near the coast, where the lidar-radar data show less low cloud than farther offshore.

Figure $9 \mathrm{~b}$ shows a scatterplot across all flights and lon' $^{\prime}$ bins of GOES low cloud fraction versus the lidar-radar low cloud fraction; they are reassuringly consistent given their different sampling and measurement approaches, with a correlation coefficient of 0.73 .

Figure 8 of Xiao et al. (2014) shows GOCCP (CALIPSO, day and night average) and MODIS (daytime only) summertime low cloud cover along the GCSS Pacific cross section slightly farther south; our CSET lidar-radar results lie between them, with a similar east-west gradient. We conclude that CSET provides a climatologically representative sample of data across the northeast Pacific $\mathrm{Sc}-\mathrm{Cu}$ transition.

\section{b. Liquid water}

Figure 10a shows $\operatorname{lon}^{\prime}-z$ composites of area-averaged "cloud water" content in droplets of less than $25 \mu \mathrm{m}$ radius, the size range measured by the CDP and consistent with the $20-30-\mu \mathrm{m}$ droplet radius threshold for rapid further collision-coalescence growth into a drizzle or rain drop (Rogers and Yau 1989, p. 121). Figure 10b shows "rainwater" content in precipitation-size drops from the 2D-C probe (which sizes drops with radii larger than $31 \mu \mathrm{m}$ ). When rainwater content is substantial, the precipitation mass in the missing $25-31-\mu$ m radius range is a small fraction of the total, so we use the sum of the $\mathrm{CDP}$ and 2D-C liquid water content as a proxy for total liquid water content.

The composite cloud water content is larger in the $\mathrm{Sc}$ region than in the $\mathrm{Cu}$ region. Even in the $\mathrm{Sc}$ region, the cloud water spans a range of altitudes, mainly due to variations in the boundary layer depth. Individual profiles in this region generally show a single stratocumulus layer less than $500 \mathrm{~m}$ thick capped by the trade inversion base, even though there may be substantial underlying cumulus or broken stratocumulus. West of $140^{\circ} \mathrm{W}$, the cloud water content is broadly distributed in the vertical between $500 \mathrm{~m}$ and the inversion layer, both in this composite and in most individual flights. The rainwater content is larger in the $\mathrm{Cu}$ region than in the Sc region, and it is distributed fairly uniformly across the boundary layer depth in both cases.

Figure 10c shows the CSET composite cloud and rainwater path (column-integrated mass) and their sum, the liquid water path (LWP), in each lon' bin. Within the cumulus regime, rainwater comprises more than half of the LWP, while cloud water comprises about $80 \%$ of the LWP in the stratocumulus regime. The scatter in Figs. 10a and 10b suggests substantial sampling uncertainties in these estimates. With this caveat, Fig. 10c also compares the CSET-mean LWP with the MACLWP climatology based on satellite microwave radiometer measurements (Elsaesser et al. 2017), sampled in 
(a)

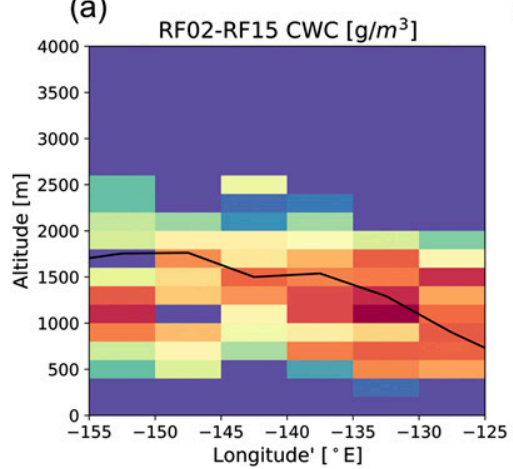

(b)

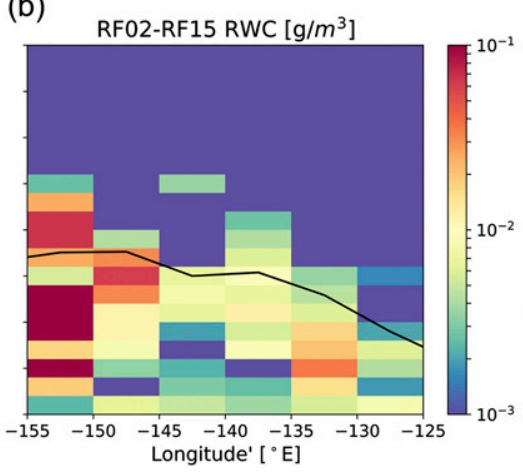

(c)

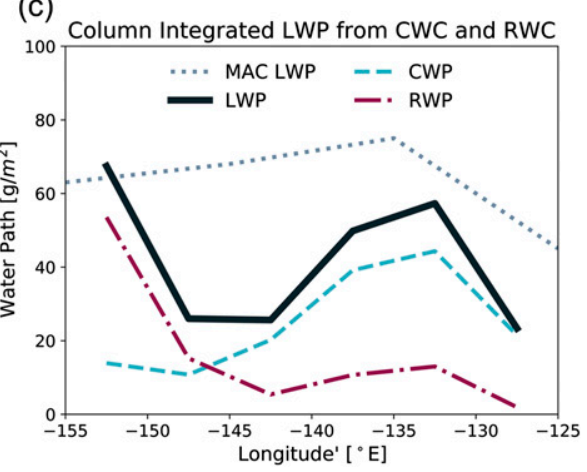

FIG. 10. All-flight composites of (a) cloud water content $(r<25 \mu \mathrm{m})$ and (b) rainwater content $(r>31 \mu \mathrm{m})$; solid black line indicates inversion base. (c) Corresponding column cloud water path (CWP, cyan) and rainwater path (RWP, magenta), which sum to the liquid water path (LWP, black). The gray dotted line shows summertime MAC-LWP climatology along the transect from satellite microwave radiometer measurements.

summertime along the CSET transect. The aircraft composite is smaller but within a factor of two of MACLWP across most of the transect. There is a diurnal cycle of boundary layer cloud and drizzle in this region, but at the mean time of in situ sampling (around 0800 local solar time on westbound flights for the Sc region, $130^{\circ}-135^{\circ} \mathrm{W}$, and 0845 local solar time on eastbound flights for the clustered $\mathrm{Cu}$ region, $145^{\circ}-150^{\circ} \mathrm{W}$ ), the in situ LWP is expected to be similar to the diurnal mean.

\section{c. Droplet and aerosol concentration}

Figure 11a shows the CDP composite in-cloud binmedian droplet concentration $N_{d}$. The hatched bins have fewer than 10 contributing in-cloud observations across all flights, but their bin-median $N_{d}$ s appear consistent with the surrounding better-sampled bins. Near the California coast, the composite $N_{d}$ ranges from 80 to $150 \mathrm{~cm}^{-3}$. West of $135^{\circ} \mathrm{W}$ the composite $N_{d}$ decreases to $30-75 \mathrm{~cm}^{-3}$ below $1 \mathrm{~km}$ and tends to decrease with height above that altitude, with values below $10 \mathrm{~cm}^{-3}$ near cloud top (darker green and blue shades) in some compositing boxes that are indicative of systematic occurrence of ultraclean layers, as extensively documented for CSET by Wood et al. (2018). O et al. (2018) explain these ultraclean layers as a result of coalescence scavenging of $\mathrm{CCN}$ in cumulus updrafts and sedimentation of droplets out of veil clouds formed in the detrainment layers of cumulus clusters.

Figure 11b shows bin-median UHSAS100, the measured concentration of accumulation mode aerosol particles with diameters between 100 and $1000 \mathrm{~nm}$. Figure $11 \mathrm{c}$ shows bin-median $\mathrm{CN}$, the concentration of aerosol particles with diameter $10-1000 \mathrm{~nm}$ measured by the condensation nucleus counter. $\mathrm{CN}$ is usually dominated by the Aitken mode (diameters 10-100 nm) but also includes the accumulation mode. As noted in section $2 \mathrm{c}$, these measurements are screened for cloud (a)

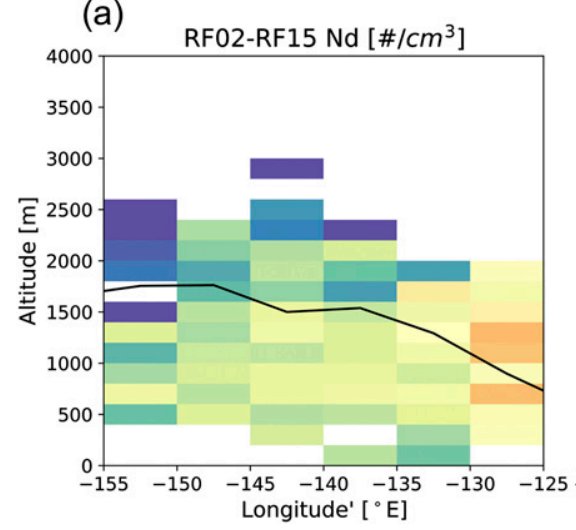

(b)

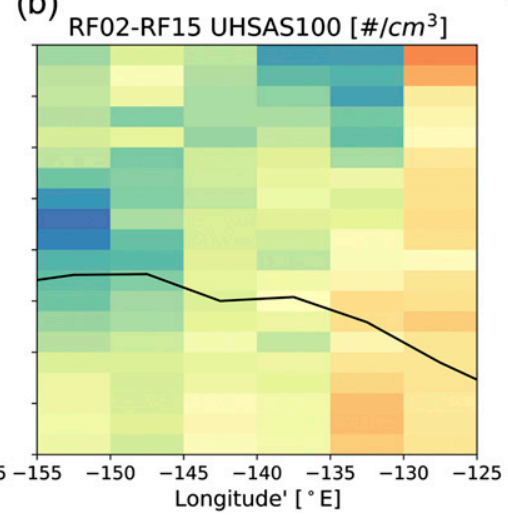

(c)

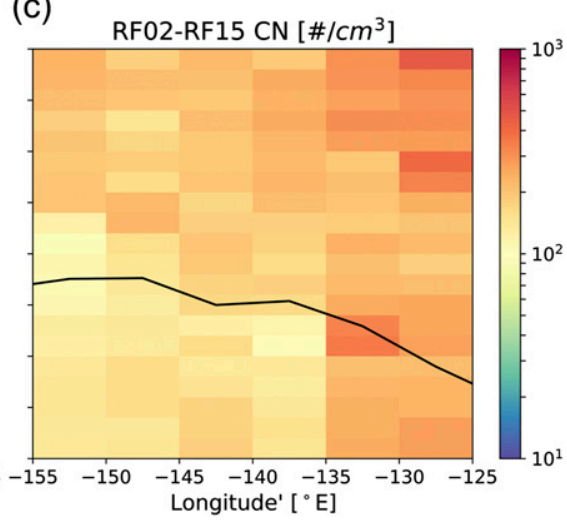

FIG. 11. All-flight composites of (a) droplet number concentration $N_{d}$, (b) accumulation-mode aerosol number concentration UHSAS100, and (c) total submicron aerosol concentration CN. Solid black line indicates inversion base. 
(a)

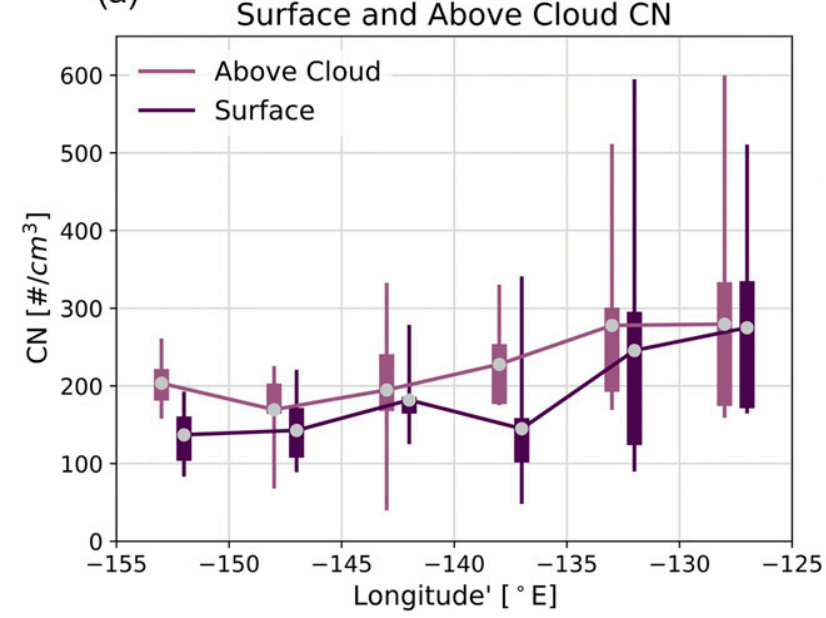

(b)

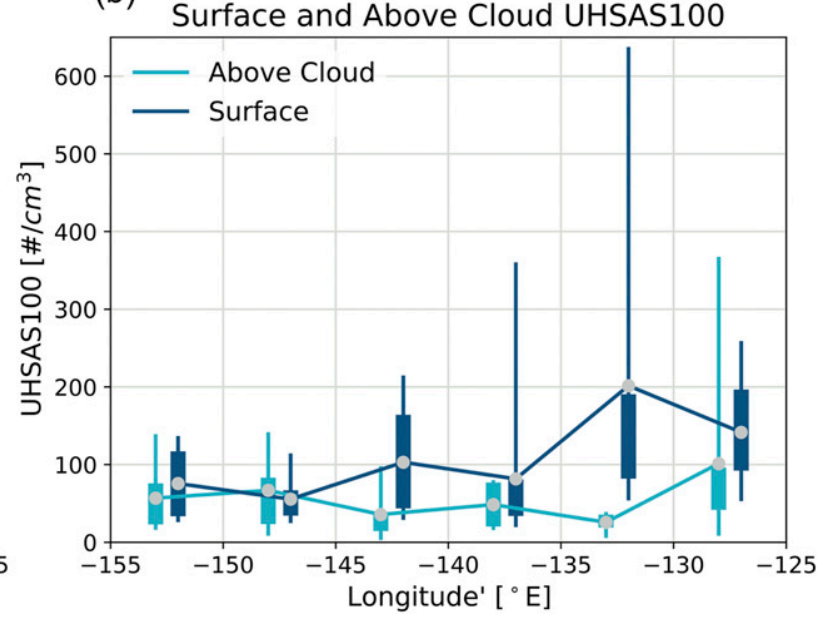

FIG. 12. Lon'-binned (a) CN and (b) UHSAS100 in two representative altitude ranges, 0-200 m (surface, dark shades) and 3000-3200 m (above cloud, light shades). Gray dots connected by colored lines show all-flight means. For each lon' bin, flight-to-flight variability is shown with a box (interquartile range) and whiskers (minimum-maximum, thin bars). Bars are offset right (left) of lon' bin center for surface (above cloud) altitude ranges.

and precipitation to minimize contamination by droplet shattering.

UHSAS100 and CN show similar trends to $N_{d}$ but more clearly, because more $1-\mathrm{Hz}$ samples are retained with out-of-cloud sampling. Relatively low UHSAS100 concentrations are found near the inversion base west of $145^{\circ} \mathrm{W}$ (Fig. 11b). Farther east, free tropospheric UHSAS100 concentrations are comparable to those below the trade inversion at most longitudes. Free tropospheric CN concentrations are mostly $200-300 \mathrm{~cm}^{-3}$, with some higher outliers near the coast. The ratio of small aerosol particles $(\mathrm{CN})$ to larger aerosol particles (UHSAS100) is systematically larger in the free troposphere than in the boundary layer. This suggests that small aerosol particles entrained into the cloud-topped boundary layer grow or coagulate, adding to its reservoir of potential CCN.

There is huge flight-to-flight variability in both $N_{d}$ and UHSAS100, presumably reflecting different airmass histories as well as intermittent injections of forest fire smoke into the lower free troposphere from British Columbia, Alaska, and California during CSET (A19). This biomass burning signal is consistent with the high $\mathrm{CO}$ concentrations seen in the composite in Fig. $7 \mathrm{~b}$. Figure 12 shows the all-flight mean of the lon'-binmedian $\mathrm{CN}$ and UHSAS100 in two representative altitude ranges, 0-200 $\mathrm{m}$ (surface) and 3000-3200 $\mathrm{m}$ (free troposphere), and box-and-whisker presentations of their flight-to-flight variability. The free tropospheric altitude range is chosen to be above the inversion for all flights and latitudes. Large variations between flights are common in both variables at both altitudes. Above the boundary layer, Aitken mode (CN minus UHSAS100) aerosol concentrations are typically $150-200 \mathrm{~cm}^{-3} \mathrm{ex}-$ cept near the coast, about twice as large as near the surface. Accumulation-mode aerosol concentrations (UHSAS100) near the surface are typically $50-100 \mathrm{~cm}^{-3}$ and often higher near the coast, with somewhat smaller values at $3 \mathrm{~km}$.

Across flights, locations and altitudes, there was a strong correlation between $N_{d}$ and UHSAS100. Figure 13 is a scatterplot of the single-flight $l^{\prime}{ }^{\prime}-z$ binmedians of these fields, for bins where both were simultaneously measured. Both fields span nearly three orders of magnitude. Their correlation coefficient on a $\log -\log$ plot is 0.71 , with a power-law best-fit $N_{d} \propto$ UHSAS $100^{0.8}$. Most of the bins scatter around a 1:1 line, but there is a tail of low-concentration bins in which the UHSAS100 concentration can be double or more the cloud droplet number concentration, suggesting activation of droplets on smaller aerosols. The lowest concentrations $\left(<10 \mathrm{~cm}^{-3}\right.$ in either variable) are indicative of ultraclean layers. They mainly occur in altitude bins above $1 \mathrm{~km}$ (yellow, green, and blue shading). In each bin, $N_{d}$ concentrations include cumulus cores (which typically have higher $N_{d}$ than thin layer clouds), resulting in a lower fraction of bins that have median droplet concentrations below the $10 \mathrm{~cm}^{-3}$ ultraclean layer threshold compared to Wood et al. (2018) and O et al. (2018).

Satellite-derived cloud-top $N_{d}$, when reliable, is an invaluable proxy for in situ $N_{d}$. For instance, Painemal et al. (2015) compared ship-based UHSAS observations during the MAGIC campaign with collocated 


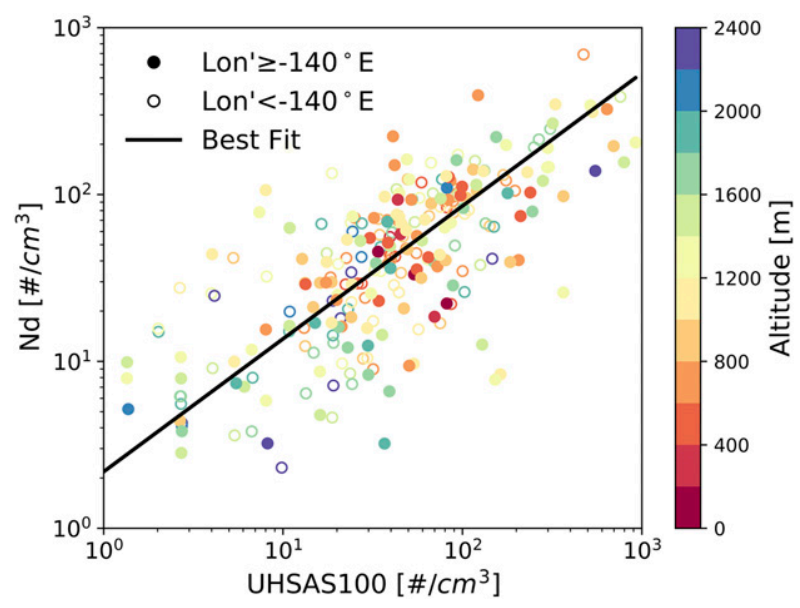

FIG. 13. Scatterplot of single-flight $\operatorname{lon}^{\prime}-z$ bin-medians of cloud droplet concentration $N_{d}$ vs accumulation-mode aerosol number concentration UHSAS100, for all bins where both were simultaneously measured. A linear fit with slope $m$ is shown in black.

geostationary $N_{d}$ retrievals of boundary layer stratocumulus cloud layers. They found a strong correlation east of $135^{\circ} \mathrm{W}$ and a weaker correlation farther west, which they interpreted as a consequence of decoupling of the deeper PBL farther to the west. We obtained similar results by correlating the lon'-binned UHSAS100 data for the subcloud legs of the CSET flights with GOES retrievals of $N_{d}$ in $2^{\circ} \times 2^{\circ}$ collocated boxes described in section $2 \mathrm{a}$ (not shown).

But particularly in the cumulus regime, the assumptions underlying the satellite retrieval are dubious, so it is important to conduct an in situ comparison with that retrieval. In Fig. 14, we compare the in situ $N_{d}$ vertically weighted by cloud water content (as a proxy for cloudtop $N_{d}$, given the range of cloud heights sampled by the G-V) with GOES retrievals of $N_{d}$ made following Painemal et al. (2015). There is a reasonable correlation, but especially to the west of $140^{\circ} \mathrm{W}$ (open circles in Fig. 14) where the cloud is more cumuliform, the GOES $N_{d}$ is often significantly lower than the in situ $N_{d}$. This could be due to a breakdown of the homogeneous plane-parallel assumption for clouds made in the GOES retrievals, to precipitation-size drops that affect the cloudtop effective radius, or to systematic vertical gradients in $N_{d}$ that make the cloud-weighted in situ $N_{d}$ a poor estimate of the cloud top $N_{d}$. More careful study is needed to fully resolve this discrepancy.

\section{d. Precipitation}

The airborne cloud radar was the primary tool for sensing precipitation in CSET. Here, we use the CSET flights to examine the precipitation frequency across the summertime $\mathrm{Sc}-\mathrm{Cu}$ transition. We use the

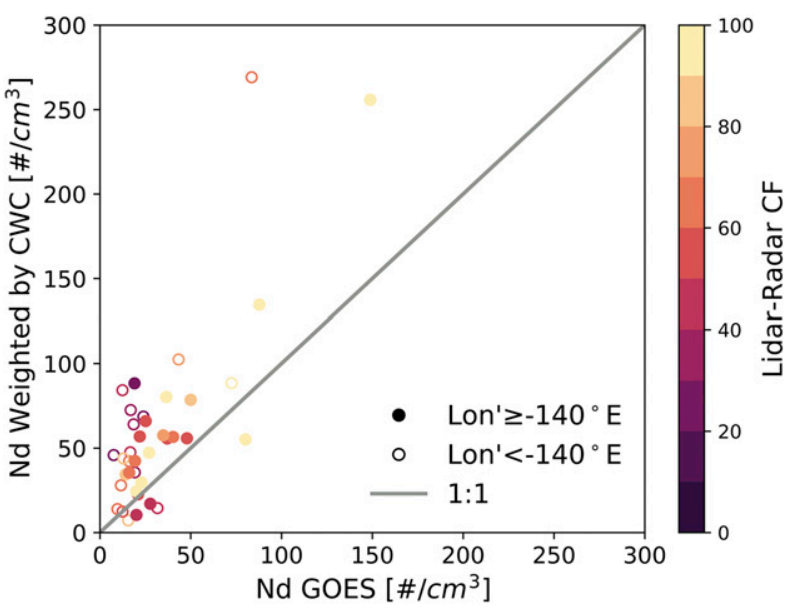

FIG. 14. Scatterplot across all flights of $5^{\circ}$ lon' bin-mean in situ $N_{d}$ vertically averaged by cloud water content weighting vs GOES $N_{d}$ retrieval in $2^{\circ} \times 2^{\circ}$ collocated boxes.

column-maximum reflectivity $\mathrm{dB} Z_{\max }$ as a precipitation proxy, and consider two thresholds: $\mathrm{dB} Z_{\max }>-10$ (light drizzle) and $\mathrm{dB} Z_{\max }>0$ (heavy drizzle). Following Eq. (10) of Comstock et al. (2004), these two thresholds correspond to cloud base precipitation fluxes of 0.3 and $2 \mathrm{~mm} \mathrm{day}^{-1}$ respectively. A pragmatic motivation for these thresholds was that the cloud radar was not sensitive enough to reliably detect weaker drizzle down to $-20 \mathrm{~dB} Z$ at the increased range needed on the survey legs.

As shown in Fig. 7 of A19, the radar was typically pointed down (up) when the aircraft was above (below) the cloud layer. We assume that the radar is oriented in the appropriate direction to sample $\mathrm{dB} Z_{\max }$ throughout. Visual inspection suggests this was generally true, although during sawtooths and level in-cloud legs there may be some underestimate of maximum radar echo.

Figure 15 shows the fraction of sampled columns in each lon' bin with reflectivity exceeding the two thresholds. For each threshold, the average over all flights is shown as a solid line. For the sectors west and east of $140^{\circ} \mathrm{W}$, the interquartile range between flights is shown as a vertical gray line segment, with a center dot showing the sectoral mean. The probability of $\mathrm{dB} Z_{\max }$ exceeding $-10(0) \mathrm{dB} Z$ was approximately $15 \%(5 \%)$ at all sampled longitudes. The occurrence fractions from individual flights varied from near zero to three times the mean in each longitude bin, with strong spatial variability associated with mesoscale regions of suppressed and enhanced precipitation. Figure 4 of a CloudSat study by Smalley and L'Ecuyer (2015) shows a map of June-July-August (JJA) mean rain occurrence frequency corresponding to a threshold of about $-7.5 \mathrm{~dB} Z$. Along the CSET cross section, values 


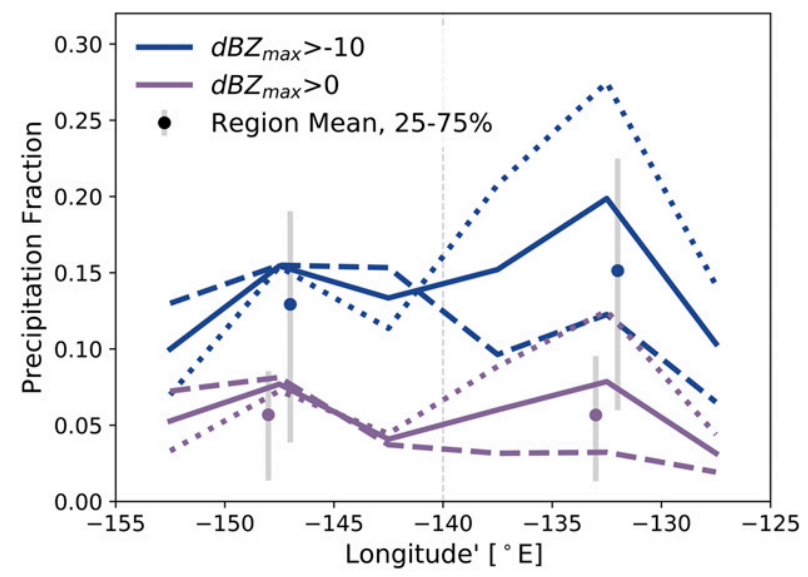

FIG. 15. Fraction of radar-sampled columns in each lon' bin with reflectivity exceeding the thresholds $-10 \mathrm{~dB} Z$ (light drizzle, blue) and $0 \mathrm{~dB} Z$ (moderate drizzle, purple). Solid lines show all-flight bin means. Dotted lines are averages over the westbound flights, which sample the Sc earlier in the day, and dashed lines are averages over the eastbound flights, which sample the $\mathrm{Cu}$ earlier in the day. Colored dots show all-flight mean precipitation fraction for the west and east sectors, separated by the thin dashed line at $l^{\prime}{ }^{\prime}=-140$. Thick gray lines (offset for the two reflectivity thresholds for clarity) indicate the interquartile range of the precipitation fraction across individual flights in these two sectors.

ranged from $8 \%$ to $12 \%$. The qualitative consistency between CSET radar observations and a comparable satellite climatology gives us confidence that CSET sampled a seasonally representative population of precipitating boundary layer clouds.

On top of this variability, there is a systematic difference between lon'-binned precipitation occurrence frequencies averaged over the westbound (dotted) and the eastbound (dashed) flights. East of $140^{\circ} \mathrm{W}$, the precipitation frequency is higher on the westbound flights. We interpret this as a manifestation of the diurnal cycle of stratocumulus precipitation, with higher precipitation frequency in the early morning than in early afternoon. On westbound (eastbound) flights, the G-V typically crossed $132.5^{\circ} \mathrm{W}$ around 0800 (1300) LST and $147.5^{\circ} \mathrm{W}$ around 1045 (0845) LST. Thus, the lower precipitation frequencies correspond to times significantly later in the day. Figure 4 of Smalley and L'Ecuyer (2015) shows a comparable result from CloudSat, with JJA precipitation frequency less than half as large at 1300 LST as at 0100 LST along the CSET transect.

\section{Role of cloud-controlling factors (EIS and $N_{d}$ )}

CSET aimed to contribute to a better understanding of the $\mathrm{Sc}-\mathrm{Cu}$ transition. In this section, we correlate the low cloud cover observed during CSET to two known controlling factors, Estimated Inversion Strength (EIS;

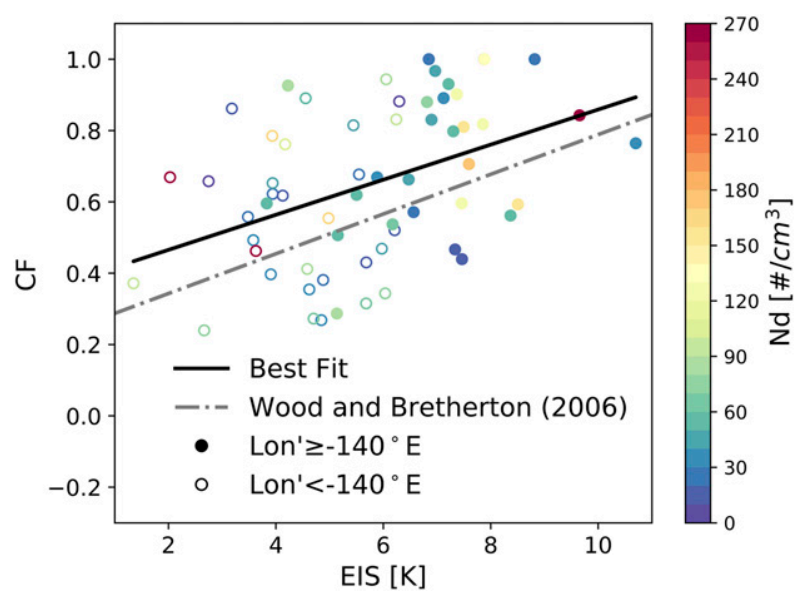

FIG. 16. Scatterplot of lidar-radar column cloud fraction for individual flights (averaged across $5^{\circ}$ lon' bins) vs EIS (from ERA5), colored by cloud droplet number concentration $N_{d}$.

Wood and Bretherton 2006) and cloud droplet number concentration $N_{d}$. Here $N_{d}$ is regarded as a marker of the interaction of aerosol with the cloud. CSET has extensive in situ $N_{d}$ and cloud fraction measurements in a regime that challenges satellite $N_{d}$ retrievals (as seen in Fig. 14), so it is well suited for disentangling cloudcontrolling effects of $N_{d}$ from those of EIS. We calculate lon'-binned EIS from ERA5 reanalysis, since the G-V profiles during low-level sampling modules often did not reach the $3 \mathrm{~km}$ elevation needed to compute it. In support of this approach, we compared EIS calculated from G-V dropsonde profiles and in situ profiles, which spanned 150-3000-m altitude, with EIS based on collocated ERA5 output. We found the ERA5 EIS to be unbiased, with a mean absolute deviation slightly larger than $1 \mathrm{~K}$ compared to the EIS derived from the G-V observations.

Figure 16 shows a scatterplot of the lon'-binned lidarradar low cloud fraction introduced in section 4 a versus EIS, colored by in situ cloud water-content weighted $N_{d}$. This shows an expected positive correlation (Klein and Hartmann 1993; Wood and Bretherton 2006) with a fit line (black) consistent with the gray seasonal mean line from Wood and Bretherton (2006). There is much more scatter than on seasonal time scales, reflecting the strong internal variability of the instantaneous cloud field. There is usually a decrease of EIS toward the west, where ocean temperatures are warmer; this results in the open circles, which come from the west sector, mainly lying to the left of the closed circles, which come from the east sector.

For a given EIS, if cloud fraction was also substantially correlated with $N_{d}$, Fig. 16 would show a vertical stratification of dot colors, but we do not see 
this. Stepwise linear regression corroborates that conclusion; after accounting for EIS, using in situ $N_{d}$ as a second predictor does not add significant skill in predicting cloud fraction.

\section{Comparison with models}

A goal of CSET was to produce a dataset useful for testing global model representations of the $\mathrm{Sc}-\mathrm{Cu}$ transition. Despite sampling and representativeness uncertainties, the composites above should prove useful comparisons for summertime climatologies from global climate models.

A more powerful model test is to sample global weather simulations of the flight days and sample them along the position and time of the flight track to compare with the observations. Since clouds and aerosols respond rapidly to synoptic variations, this allows every flight to be used as a quasi-independent test of the model.

We compare two simple approaches. The first is to sample a global reanalysis. We use NASA's ModernEra Retrospective Analysis for Research and Applications, version 2, or MERRA-2 (Gelaro et al. 2017, data used here obtained from https://disc.gsfc.nasa.gov/ datasets). MERRA-2 has 72 vertical levels and approximately $60 \mathrm{~km}$ horizontal grid spacing. It includes a selection of chemical species and aerosols. Neither the CSET in situ airborne observations nor dropsondes were transmitted to forecast centers, so they are independent checks on this reanalysis. The second approach is to use a global climate model. We use version 6 of the Community Atmosphere Model (CAM6), with the wind, temperature and surface pressure fields (but not humidity, clouds, or aerosols) nudged at every grid point toward a time/space interpolated version of MERRA-2 using a 24-h relaxation time scale. The CAM6 data used here can be requested from A. Gettelman (andrew@ucar.edu).Wu et al. (2017) describe an earlier application of this approach to CAM5 for the HIAPER Pole-to-Pole Observations (HIPPO) campaign in 2009-11, with a focus on ice cloud microphysics.

CAM6 has 32 vertical levels and approximately $1^{\circ}$ horizontal grid spacing. The purpose of this second approach is to test the skill of CAM6 in representing clouds, aerosols and boundary layer structure when constrained to approximately follow the observed weather. Because humidity and clouds are freely evolving in this framework, they can develop errors that can point to needed model improvements. We now show an illustrative example of this methodology; its systematic exploitation for CSET (particularly for aerosols and warm cloud microphysics) is left for a sequel.
Figure 17 shows a comparison of the RF10 measurements of relative humidity and cloud water content with MERRA-2 and nudged CAM6, each sampled along the latitude, longitude, and time of the flight path. Since CAM6 is nudged toward MERRA-2 meteorology, differences in humidity and cloud fields in the two models likely stem mainly from their different parameterized cloud and boundary layer physics.

The top of the "moist layer" of high RH is a marker of boundary layer height. MERRA-2 captures most of the longitudinal variability in RH (Fig. 17a) and places the boundary layer stratocumulus top at approximately the right height (Fig. 17c). The steady increase of RH between the surface and $1 \mathrm{~km}$ altitude indicates a wellmixed boundary layer in MERRA-2 east of lon' $^{\prime}=$ $140^{\circ} \mathrm{W}$, while the observed $\mathrm{RH}$ already shows a weaker increase with height at $\operatorname{lon}^{\prime}=135^{\circ} \mathrm{W}$ and even in the profile just east of $\operatorname{lon}^{\prime}=130^{\circ} \mathrm{W}$, indicative of weak decoupling. The nudged CAM6 simulates a shallower moist layer than observed across most of the flight track (Fig. 17b). In the east sector of the cross section, both models, especially MERRA-2, simulate stratocumulus layers that are vertically diffuse compared to the observed cloud water (Figs. 17c,d), an expected consequence of comparing point samples with gridbox averages. MERRA-2 simulates more cloud water than CAM6 in the shallow cumulus regime to the west of the in situ sampling. These trends are also evident in all-flight averages of these comparisons (not shown).

MERRA-2 also provides $\mathrm{O}_{3}$ and $\mathrm{CO}$ concentration estimates. Figure 18 compares these with the in situ data for RF10. MERRA-2 overestimates the distinctly lower in situ $\mathrm{O}_{3}$ concentrations below the inversion for this and other CSET flights, suggesting that ozone loss processes in the boundary layer are underestimated. The MERRA-2 CO is somewhat lower than the in situ observations.

\section{Summary}

CSET was the first airborne field study to gather extensive in situ observations across the entire summertime northeast Pacific $\mathrm{Sc}-\mathrm{Cu}$ transition. CSET was designed for Lagrangian sampling of this transition, as discussed by A19 and a companion paper by Mohrmann et al. (2019, manuscript submitted to Mon. Wea. Rev.). In the process, the 14 CSET flights also gathered a superb quasi-Eulerian dataset representative of a line between Northern California and Hawaii, slightly north of the nearby GPCI and MAGIC cross sections. We have presented an Eulerian view of the $\mathrm{Sc}-\mathrm{Cu}$ transition and its synoptic variability based on these flights, including unique new in situ vertically resolved measurements of 
(a)

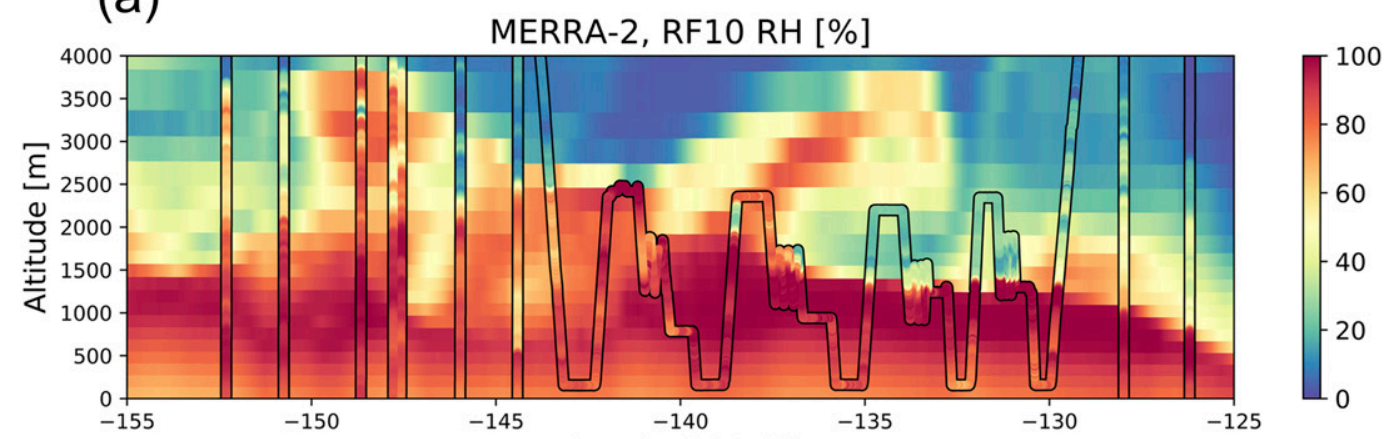

(b)

Longitude' [ $\left.{ }^{\circ} \mathrm{E}\right]$

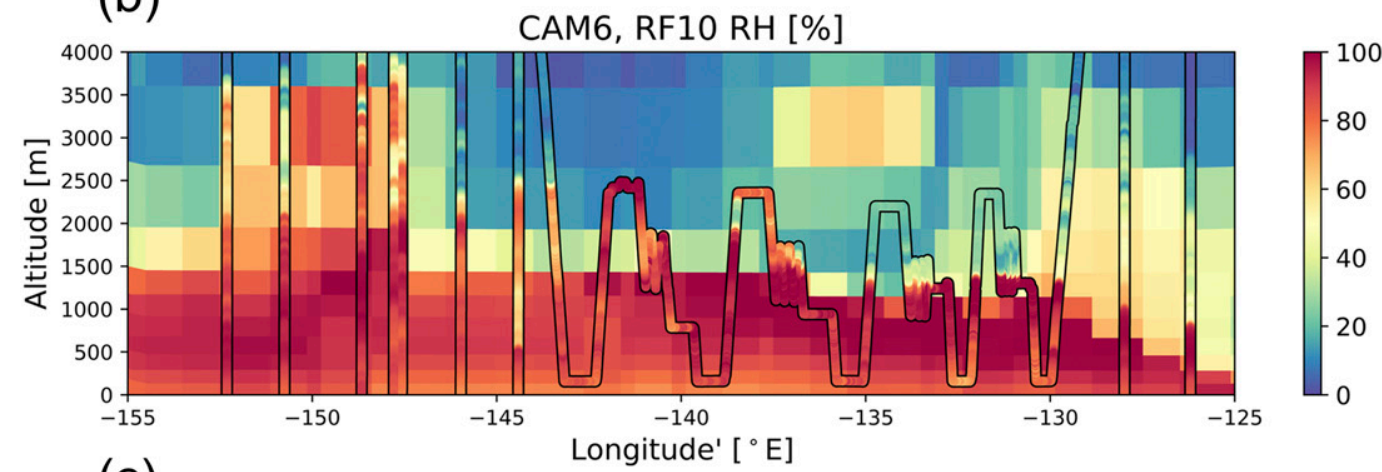

(c)

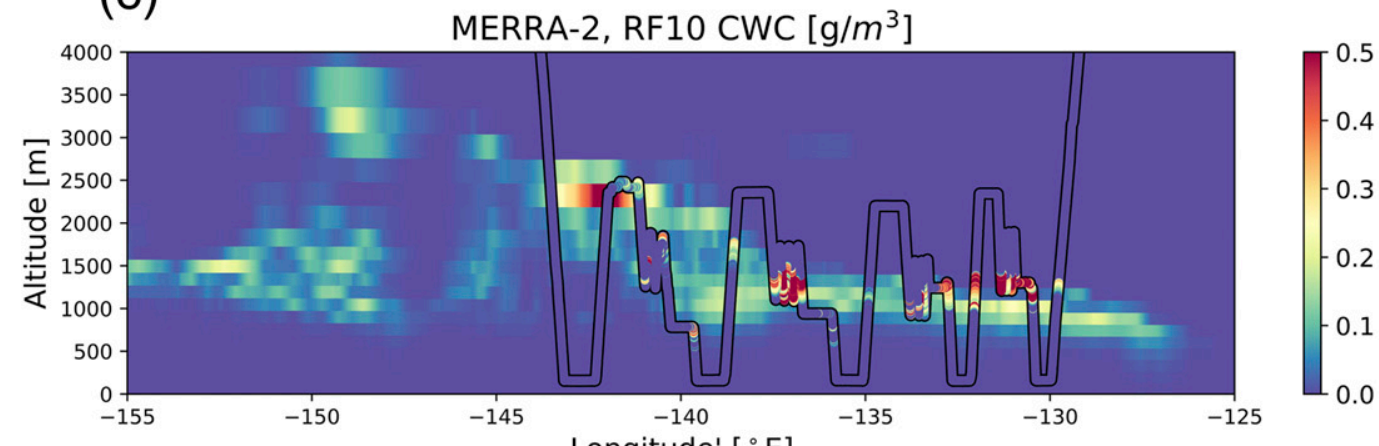

(d)

Longitude' [ ${ }^{\circ} \mathrm{E}$ ]

CAM6, RF10 CWC $\left[\mathrm{g} / \mathrm{m}^{3}\right]$

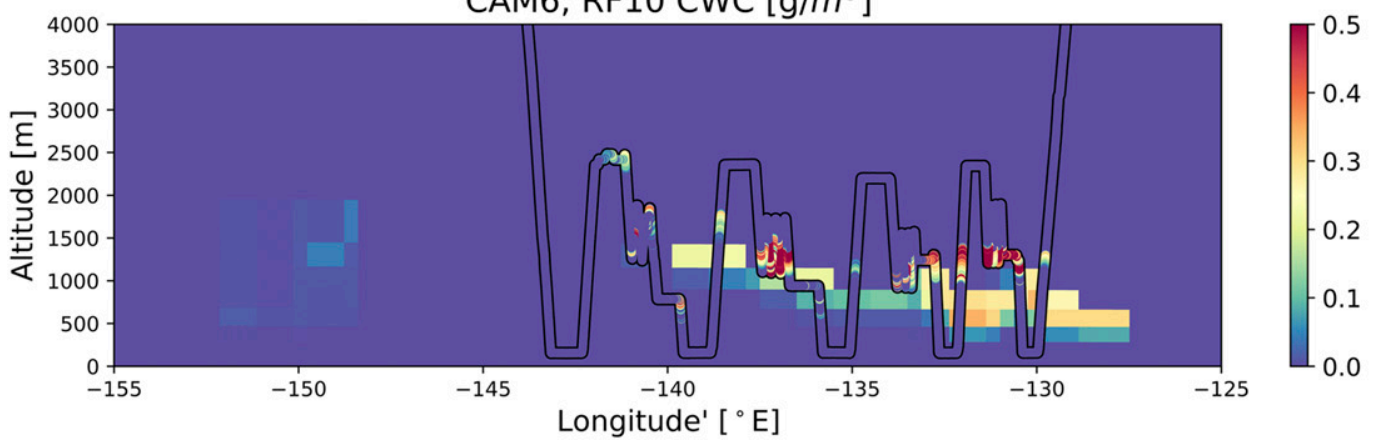

FIG. 17. Comparison of RF10 measurements (colored channels) of relative humidity and cloud water content with MERRA-2 and nudged CAM6, each sampled along the latitude, longitude, and time of the flight path and indicated by the background shading. 
(a)

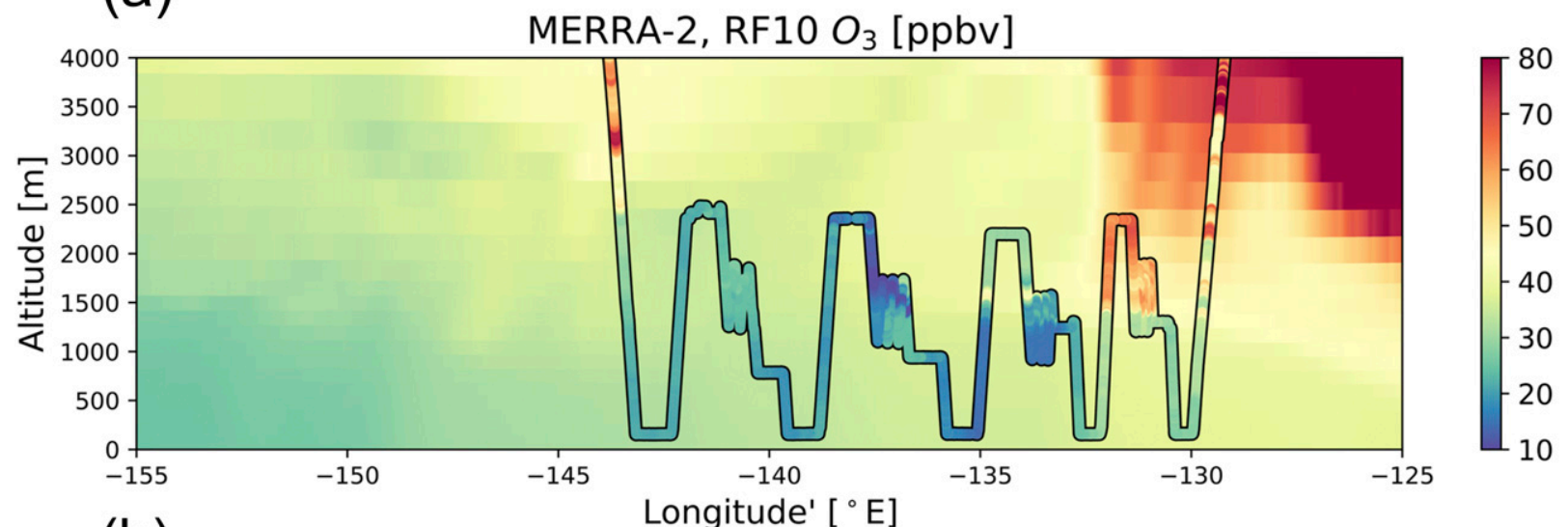

(b)

Longitude' [ $\left.{ }^{\circ} \mathrm{E}\right]$

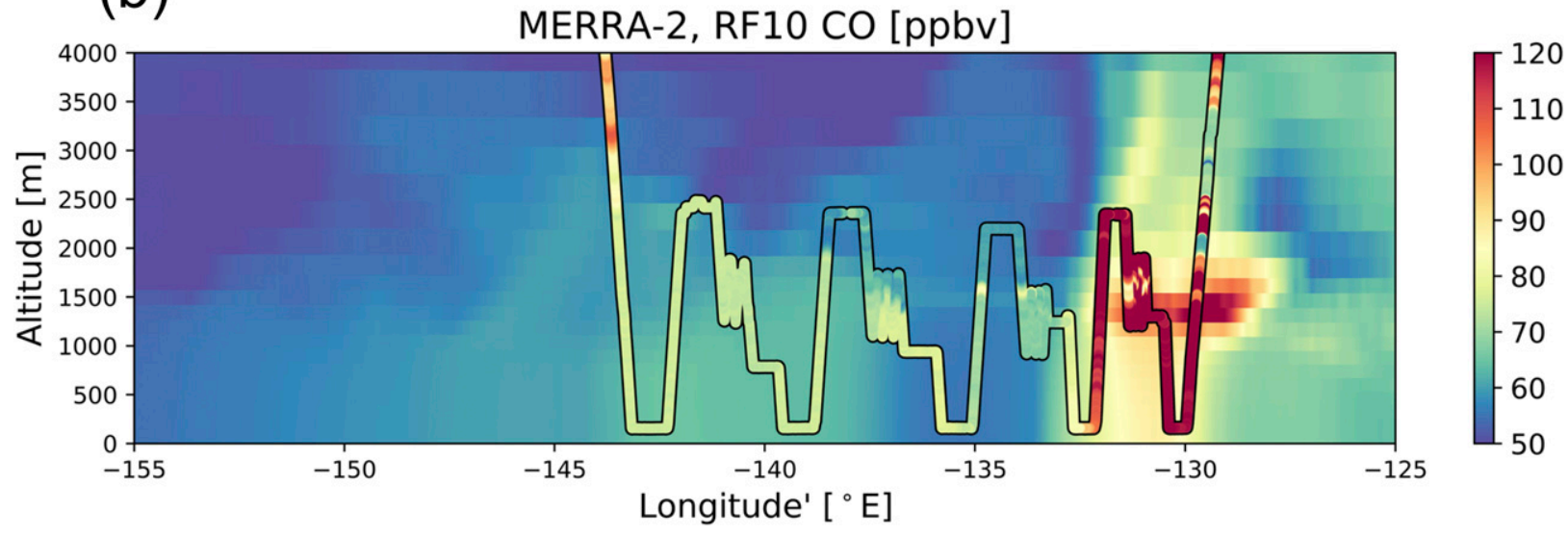

FIG. 18. Comparison of RF10 measurements (colored channels) of (a) ozone $\left(\mathrm{O}_{3}\right)$ and (b) carbon monoxide (CO) with MERRA-2 (background shading), sampled along the latitude, longitude, and time of the flight path.

turbulence, cloud microphysics, aerosol characteristics, trace gases, and vertically pointing W-band radar and lidar returns. We developed a longitude-height binning and compositing strategy to mitigate limitations of sparse sampling and internal spatial and temporal variability.

Overall, the observed characteristics of the $\mathrm{Sc}-\mathrm{Cu}$ transition matched expectations, with a Sc-topped boundary layer becoming systematically more decoupled farther to the southwest, followed by a cloudiness transition at $135^{\circ}-145^{\circ} \mathrm{W}$ into precipitating cumulus clusters organized on $100-\mathrm{km}+$ scales. These clusters were surrounded by patches of thin Sc ("veil clouds") and often ultraclean layers near the trade inversion base, as analyzed by Wood et al. (2018).

The fractional coverage of the Sc patches diminished toward Hawaii, where the inversion base was typically $2 \mathrm{~km}$. Multiscale cloud organization was apparent throughout the flights.

Aircraft lidar-measured low cloud cover, averaged during each flight over $5^{\circ}$ longitude bins, was positively correlated with estimated inversion strength
(EIS) with a regression slope close to past climatology. After controlling for EIS, the low cloud cover was not well correlated with cloud droplet concentration, which suggests that the $\mathrm{Sc}-\mathrm{Cu}$ transition is not strongly controlled by aerosol processes. This contrasts with some recent idealized large-eddy simulation studies (e.g., Yamaguchi et al. 2017), but is consistent with another such study using data-constrained forcings and boundary conditions (McGibbon and Bretherton 2017).

The CSET lidar-radar cloud fraction compared well with GOES satellite retrievals of cloud fraction, but the GOES retrievals of droplet concentration for CSET were often biased low, especially in the cumulus regime. This issue merits further investigation.

In almost all flights and regimes, the thickest clouds were precipitating, but the areal coverage of columnmaximum radar echoes exceeding $0 \mathrm{~dB} Z$ was only about $5 \%$ in both $\mathrm{Cu}$ and $\mathrm{Sc}$ regimes, with more extensive precipitation earlier in the morning. The ultraclean layers observed in accumulation mode aerosol and cloud droplet concentration are evidence of active 
aerosol-cloud-precipitation feedbacks within the cumulus clusters.

The flights measured the partitioning of liquid water between cloud ( $<25 \mu \mathrm{m}$ droplet radius) and drizzle/rain (larger drops). This was highly variable, but in general, in the shallow boundary layers typically seen farther east, most of the liquid water is cloud, while farther west, where $\mathrm{Cu}$ occasionally reached $4 \mathrm{~km}$ deep, the average column mass of drizzle and rain was larger than that of cloud. A multiflight composite of the column-integrated liquid water is within a factor of 2 of a satellite climatology of liquid water path (MAC-LWP) during summertime at most longitudes across this transect.

Above the boundary layer, Aitken mode aerosol concentration was typically $150-200 \mathrm{~cm}^{-3}$, about twice as much as near the surface. Accumulation-mode aerosol concentration near the surface was typically $50-100 \mathrm{~cm}^{-3}$, and often higher near the coast, with somewhat smaller values at $3 \mathrm{~km}$. Within the boundary layer, cloud droplet number correlated quite well with accumulation mode aerosol number concentration from the same height. Smoke from some large forest fires advected over the region, producing spikes of aerosol, $\mathrm{CO}$ and $\mathrm{O}_{3}$ on some flights. The $\mathrm{CO}$ mixed down into the boundary layer with little systematic gradient at the inversion, but the $\mathrm{O}_{3}$ was half or less as large within the boundary layer as above, particularly in the deeper $\mathrm{Cu}$ boundary layers at the west end of the trajectory.

Measured profiles of turbulent kinetic energy dissipation rate across the transition are presented as a possible comparison for LES and those GCM parameterizations of subtropical cloud-topped boundary layers that compute dissipation.

Last, we showed a single-flight comparison of the CSET dataset with space-time collocated output from the MERRA-2 global reanalysis and the CAM6 climate model nudged toward MERRA-2 winds and temperatures. MERRA-2 compares well with the aircraftmeasured trade inversion base; CAM6 has a slightly lower inversion base. Both models vertically diffuse the observed stratocumulus cloud layers. In a future paper, we intend to use such comparisons more systematically as a tool for GCM diagnosis and improvement of parameterized cloud and aerosol processes. The breadth of CSET observations analyzed in this paper provides a unique and rigorous test of GCM performance across a subtropical Sc-Cu transition.

Acknowledgments. The success of CSET is primarily due to the dedicated staff of NCAR's Research Aviation Facility who operated the G-V and its core instrumentation, provided invaluable advice about analyzing the data, and made CSET a pleasure for its scientific participants. The authors wish to acknowledge support from NSF grants AGS-1445813, AGS-1445832, and AGS-1445831. I. McCoy was supported by the National Science Foundation Graduate Research Fellowship Program under grant DGE-1762114. V. Ghate acknowledges support from the U.S. Department of Energy's (DOE) Atmospheric System Research (ASR) under Contract DE-AC02-06CH11357 awarded to Argonne National Laboratory, and computing resources provided on Blues, a high-performance computing cluster operated by the Laboratory Computing Resource Center (LCRC) at Argonne National Laboratory.

\section{APPENDIX}

\section{Estimate of TKE Dissipation from Airborne Measurements Using High-Frequency Vertical Velocity Variability}

In homogeneous isotropic turbulence with TKE dissipation rate $\varepsilon$ per unit volume, the power spectrum of the vertical velocity has the form

$$
P_{w w}(k)=0.8 \varepsilon^{2 / 3} k^{-5 / 3},
$$

where $k$ is wavenumber (e.g., Garratt 1992, p. 71). Our goal is to use this formula to derive a spatially localized estimate for $\varepsilon$. Our approach is broadly based on Cornish et al. (2006). Like that study we infer $\varepsilon$ from high-frequency vertical velocity fluctuations, but our approach is based on time-windowed statistics rather than their more sophisticated but also more complex wavelet filtering method.

For a plane obtaining a time series of vertical velocity fluctuation $w^{\prime}(t)$ by flying horizontally through the turbulence at speed $U_{0}$, the wavenumber $k$ is equivalent to a frequency $f=k U_{0} / 2 \pi$ and the temporal power spectrum is

$$
P_{w w}(f)=0.8\left(\frac{U_{0}}{2 \pi}\right)^{2 / 3} \varepsilon^{2 / 3} f^{-5 / 3}
$$

During CSET, the velocity components were all measured using pressure transducers and provided at $25 \mathrm{~Hz}$. On level subcloud legs, in which the turbulence usually appears fairly homogeneous, the power spectrum of vertical velocity fluctuations $w^{\prime}$ follows the expected Kolmogorov $k^{-5 / 3}$ spectrum between $0.5 \mathrm{~Hz}$ and the Nyquist frequency of $12.5 \mathrm{~Hz}$. On the other hand, the power spectra of horizontal velocity fluctuations hit white noise floors at $1 \mathrm{~Hz}$ in the direction of aircraft motion and $5 \mathrm{~Hz}$ in the transverse direction, suggesting that they have larger measurement errors. Thus we 
estimate $\varepsilon$ from $w^{\prime}$, filtered to only retain frequencies within the inertial range.

This can be done in many ways. We chose to chunk $w^{\prime}$ into windows of length $\tau=1 \mathrm{~s}$, each corresponding to a second of aircraft sampling with $N=25$ samples. Within each window, we choose $w_{\mathrm{hi}}^{\prime}$ to be the $25-\mathrm{Hz}$ vertical velocity fluctuation about the 1 -s mean and define $w_{\mathrm{hi}}^{\prime} w_{\mathrm{hi}}^{\prime}$ as the "high-pass" sample variance of $w_{\mathrm{hi}}^{\prime}$ within that window. The tilde indicates that this is a sample variance calculated every $1 \mathrm{~s}$. If the turbulence is assumed to be statistically stationary over some interval, we can define $\overline{w_{\mathrm{hi}}^{\prime} w_{\mathrm{hi}}^{\prime}}$ to be the expected highpass variance averaged over many samples, denoted by an overline. This has the nice property that it can be added to the $1-\mathrm{Hz}$ vertical velocity variance to get the full $25-\mathrm{Hz}$ vertical velocity variance; it mainly responds to frequencies of $1-2 \mathrm{~Hz}$.

We chose a $1-\mathrm{Hz}$ turbulence measure because it is convenient for correlating with other aircraftmeasured quantities such as liquid water content (see Wood et al. 2018 for an application to clouds in ultraclean layers). However, the $1-\mathrm{Hz}$ estimate is quite variable, even in homogeneous turbulence, because TKE dissipation is distributed highly nonuniformly within a turbulent fluid. We find that $20 \mathrm{~s}$ or longer averages of $\overline{w_{\mathrm{hi}}^{\prime} w_{\mathrm{hi}}^{\prime}}$ smooth out much of this intrinsic variability to give a more robust estimate of $\overline{w_{\mathrm{hi}}^{\prime} w_{\mathrm{hi}}^{\prime}}$. The binning used for our single-flight composites effectively does this. When the plane is sampling along a level leg, a $5^{\circ}$ lon'-200-m height bin will naturally include at least $10 \mathrm{~min}$ of sampling. During G-V climbs and descents, the plane maintained a vertical velocity of approximately $7.5 \mathrm{~m} \mathrm{~s}^{-1}$, traversing a $200-\mathrm{m}$ vertical bin in approximately $27 \mathrm{~s}$. Thus, for each flight we use the bin-mean of $\overline{w_{\mathrm{hi}}^{\prime} w_{\mathrm{hi}}^{\prime}}$, which we denote by angle brackets, to locally estimate

$$
\overline{w_{\mathrm{hi}}^{\prime} w_{\mathrm{hi}}^{\prime}} \approx \overline{w_{\mathrm{hi}}^{\prime} w_{\mathrm{hi}}^{\prime}} \text {. }
$$

From $\overline{w_{\mathrm{hi}}^{\prime} w_{\mathrm{hi}}^{\prime}}$ we can estimate the dissipation rate $\varepsilon$. Within each $1 \mathrm{~s}$ window, we can Fourier analyze $w^{\prime}$ into the frequencies $f_{j}=j \Delta f, \Delta f=1 / \tau, j=0,1, \ldots,(N-1) / 2$; $w_{\mathrm{hi}}^{\prime}$ is obtained by removing the zero-frequency component from $w^{\prime}$. The expected value of the remaining variance is

$$
\begin{aligned}
\overline{w_{\mathrm{hi}}^{\prime} w_{\mathrm{hi}}^{\prime}} & =\sum_{j=1}^{(N-1) / 2} P_{w w}\left(f_{j}\right) \Delta f=0.8\left(\frac{U_{0}}{2 \pi}\right)^{2 / 3} \varepsilon^{2 / 3} \\
& \times \sum_{j=1}^{(N-1) / 2} f_{j}^{-5 / 3} \Delta f=0.8 a\left(\frac{U_{0} \tau \varepsilon}{2 \pi}\right)^{2 / 3},
\end{aligned}
$$

where

$$
a=\sum_{j=1}^{(N-1) / 2} j^{-5 / 3}=1.85
$$

Approximately half of the high-pass variance comes from the $1-\mathrm{Hz}$ frequency, and the rest comes from the higher harmonics. This can be solved for the estimated TKE dissipation rate:

$$
\begin{aligned}
& \varepsilon \approx\left(C / U_{0} \tau\right) \overline{w_{\mathrm{hi}}^{\prime} w_{\mathrm{hi}}^{\prime}}{ }^{3 / 2}, \quad C=2 \pi /(0.8 a)^{3 / 2}=3.5, \\
& \tau=1 \mathrm{~s} .
\end{aligned}
$$

\section{REFERENCES}

Ahlgrimm, M., R. Forbes, R. J. Hogan, and I. Sandu, 2018: Understanding global model systematic shortwave radiation errors in subtropical marine boundary layer cloud regimes. J. Adv. Model. Earth Syst., 10, 2042-2060, https://doi.org/ 10.1029/2018MS001346.

Albrecht, B. A., C. S. Bretherton, D. Johnson, W. Schubert, and A. S. Frisch, 1995: The Atlantic Stratocumulus Transition Experiment (ASTEX). Bull. Amer. Meteor. Soc., 76, 889-903, https://doi.org/10.1175/1520-0477(1995)076<0889: TASTE $>2.0 . \mathrm{CO} ; 2$.

— , and Coauthors, 2019: Cloud System Evolution in the Trades (CSET): Following the evolution of boundary layer cloud systems with the NSF-NCAR GV. Bull. Amer. Meteor. Soc., 100, 93-121, https://doi.org/10.1175/BAMS-D-17-0180.1.

Bretherton, C. S., and R. Pincus, 1995: Cloudiness and marine boundary layer dynamics in the ASTEX Lagrangian experiments. Part I: Synoptic setting and vertical structure. J. Atmos. Sci., 52, 2707-2723, https://doi.org/10.1175/1520-0469(1995) 052<2707:CAMBLD $>2.0$. CO;2.

— spheric stability, and decoupling of cloud-topped boundary layers. J. Atmos. Sci., 54, 148-167, https://doi.org/10.1175/ 1520-0469(1997)054<0148:MTLTSA > 2.0.CO;2.

_- P. Austin, and S. T. Siems, 1995: Cloudiness and marine boundary layer dynamics in the ASTEX Lagrangian experiments. Part II: Cloudiness, drizzle, surface fluxes, and entrainment. J. Atmos. Sci., 52, 2724-2735, https:// doi.org/10.1175/1520-0469(1995)052<2724:CAMBLD> 2.0.CO;2.

— S. K. Krueger, M. C. Wyant, P. Bechtold, E. van Meijgaard, B. Stevens, and J. Teixeira, 1999: A GCSS boundary layer model intercomparison study of the first ASTEX Lagrangian experiment. Bound.-Layer Meteor., 93, 341-380, https:// doi.org/10.1023/A:1002005429969.

Comstock, K. K., R. Wood, S. E. Yuter, and C. S. Bretherton, 2004: Reflectivity and rain rate in and below drizzling stratocumulus. Quart. J. Roy. Meteor. Soc., 130, 2891-2918, https://doi.org/10.1256/qj.03.187.

Cornish, C. R., C. S. Bretherton, and D. B. Percival, 2006: Maximal overlap wavelet statistical analysis with application to atmospheric turbulence. Bound.-Layer Meteor., 119, 339-374, https://doi.org/10.1007/s10546-005-9011-y.

Cuijpers, J. W. M., and P. G. Duynkerke, 1993: Large eddy simulation of trade wind cumulus clouds. J. Atmos. Sci., 50, 3894-3908, https://doi.org/10.1175/1520-0469(1993) 050<3894:LESOTW $>2.0$. CO;2. 
Elsaesser, G. S., C. W. O’Dell, M. D. Lebsock, R. Bennartz, T. J Greenwald, and F. J. Wentz, 2017: The Multisensor Advanced Climatology of Liquid Water Path (MAC-LWP). J. Climate, 30, $10193-10210$, https://doi.org/10.1175/JCLID-16-0902.1.

Garratt, J. R., 1992: The Atmospheric Boundary Layer. Cambridge University Press, $316 \mathrm{pp}$.

Gelaro, R., and Coauthors, 2017: The Modern-Era Retrospective Analysis for Research and Applications, Version 2 (MERRA-2). J. Climate, 30, 5419-5454, https://doi.org/10.1175/ JCLI-D-16-0758.1.

Heffter, J. L., 1980: Transport layer depth calculations. Proc. Second Joint Conf. on Applications of Air Pollution Meteorology, New Orleans, LA, Amer. Meteor. Soc., 787-791.

Jones, C. R., C. S. Bretherton, and D. Leon, 2011: Coupled vs. decoupled boundary layers in VOCALS-REx. Atmos. Chem. Phys., 11, 7143-7153, https://doi.org/10.5194/acp-117143-2011.

Kalmus, P., M. Lebsock, and J. Teixeira, 2014: Observational boundary layer energy and water budgets of the stratocumulus-to-cumulus transition. J. Climate, 27, 91559170, https://doi.org/10.1175/JCLI-D-14-00242.1.

_ S. Wong, and J. Teixeira, 2015: The Pacific subtropical cloud transition: A MAGIC assessment of AIRS and ECMWF thermodynamic structure. IEEE Geosci. Remote Sens. Lett., 12, 1586-1590, https://doi.org/10.1109/LGRS.2015.2413771.

Klein, S. A., and D. L. Hartmann, 1993: The seasonal cycle of low stratiform clouds. J. Climate, 6, 1587-1606, https://doi.org/ 10.1175/1520-0442(1993)006<1587:TSCOLS $>2.0$.CO;2.

Krueger, S. K., G. T. McLean, and Q. Fu, 1995a: Numerical simulations of the stratus to cumulus transition in the subtropical marine boundary layer. Part I: Boundary-layer structure. J. Atmos. Sci., 52, 2839-2850, https://doi.org/ 10.1175/1520-0469(1995)052<2839:NSOTST > 2.0.CO;2.

$\ldots$, , and 1995b: Numerical simulation of the stratusto-cumulus transition in the subtropical marine boundary layer. Part II: Boundary-layer circulation. J. Atmos. Sci., 52, 2851-2868, https://doi.org/10.1175/1520-0469(1995)052<2851: NSOTST $>2.0 . \mathrm{CO} ; 2$.

Lothon, M., D. H. Lenschow, D. Leon, and G. Vali, 2005: Turbulence measurements in marine stratocumulus with airborne Doppler radar. Quart. J. Roy. Meteor. Soc., 131, 2063-2080, https://doi.org/10.1256/qj.04.131.

McGibbon, J., and C. S. Bretherton, 2017: Skill of ship-following large-eddy simulations in reproducing MAGIC observations across the Northeast Pacific stratocumulus to cumulus transition region. J. Adv. Model. Earth Syst., 9, 810-831, https:// doi.org/10.1002/2017MS000924.

Minnis, P., and Coauthors, 2008: Near-real time cloud retrievals from operational and research meteorological satellites. Proc. SPIE, 7107, 710703, https://doi.org/10.1117/12.800344.

O, K.-T., R. Wood, and C. S. Bretherton, 2018: Ultraclean layers and optically thin clouds in the stratocumulus-tocumulus transition. Part II: Depletion of cloud droplets and cloud condensation nuclei through collision-coalescence. J. Atmos. Sci., 75, 1653-1673, https://doi.org/10.1175/JAS-D-17-0218.1.

Painemal, D., and P. Zuidema, 2011: Assessment of MODIS cloud effective radius and optical thickness retrievals over the Southeast Pacific with VOCALS-REx in-situ measurements. J. Geophys. Res., 116, D24206, https://doi.org/ 10.1029/2011JD016155.

—_ P. Minnis, and M. Nordeen, 2015: Aerosol variability, synoptic-scale processes, and their link to the cloud microphysics over the northeast Pacific during MAGIC. J. Geophys. Res. Atmos., 120, 5122-5139, https://doi.org/ 10.1002/2015JD023175.

Rogers, R. R., and M. K. Yau, 1989: A Short Course in Cloud Physics. 3rd ed. Pergamon Press, 290 pp.

Schwartz, M. C., and Coauthors, 2019: Merged cloud and precipitation dataset from the HIAPER-GV for the Cloud System Evolution in the Trades (CSET) Campaign. J. Atmos. Oceanic Technol., https://doi.org/10.1175/JTECHD-18-0111.1, in press.

Smalley, M., and T. L'Ecuyer, 2015: A global assessment of the spatial distribution of precipitation occurrence. J. Appl. Meteor. Climatol., 54, 2179-2197, https://doi.org/10.1175/ JAMC-D-15-0019.1.

Teixeira, J., and Coauthors, 2011: Tropical and subtropical cloud transitions in weather and climate prediction models: The GCSS/WGNE Pacific Cross-Section Intercomparison (GPCI). J. Climate, 24, 5223-5256, https://doi.org/10.1175/ 2011JCLI3672.1.

van der Dussen, J. J., and Coauthors, 2013: The GASS/EUCLIPSE model intercomparison of the stratocumulus transition as observed during ASTEX: LES results. J. Adv. Model. Earth Syst., 5, 483-499, https://doi.org/10.1002/jame.20033.

Wood, R., and C. S. Bretherton, 2006: On the relationship between stratiform low cloud cover and lower tropospheric stability. J. Climate, 19, 6425-6432, https://doi.org/10.1175/JCLI3988.1. , and Coauthors, 2018: Ultraclean layers and optically thin clouds in the stratocumulus-to-cumulus transition. Part I: Observations. J. Atmos. Sci., 75, 1631-1652, https://doi.org/ 10.1175/JAS-D-17-0213.1.

Wu, C., X. Liu, M. Diao, K. Zhang, A. Gettelman, Z. Lu, J. E. Penner, and Z. Lin, 2017: Direct comparisons of ice cloud macro- and microphysical properties simulated by the Community Atmosphere Model version 5 with HIPPO aircraft observations. Atmos. Chem. Phys., 17, 4731-4749, https:// doi.org/10.5194/acp-17-4731-2017.

Wyant, M. C., C. S. Bretherton, H. A. Rand, and D. E. Stevens, 1997: Numerical simulations and a conceptual model of the stratocumulus to trade cumulus transition. J. Atmos. Sci., 54, 168-192, https://doi.org/10.1175/1520-0469(1997)054<0168: NSAACM $>2.0 . \mathrm{CO} ; 2$.

Xiao, H., and Coauthors, 2014: Diagnosis of the marine low cloud simulation in the NCAR Community Earth System Model (CESM) and the NCEP Global Forecast System (GFS)Modular Ocean Model v4 (MOM4) coupled model. Climate Dyn., 43, 737-752, https://doi.org/10.1007/s00382-014-2067-y

Yamaguchi, T., G. Feingold, and J. Kazil, 2017: Stratocumulus to cumulus transition by drizzle. J. Adv. Model. Earth Syst., 9, 2333-2349, https://doi.org/10.1002/2017MS001104.

Zhou, X., P. Kollias, and E. R. Lewis, 2016: Clouds, precipitation, and marine boundary layer structure during the MAGIC field campaign. J. Climate, 28, 2420-2442, https://doi.org/10.1175/ JCLI-D-14-00320.1. 